\title{
ANALYSIS OF AN OPTICAL GATE DEVICE FOR MEASURING AEOLIAN SAND MOVEMENT
}

ABSTRACT

Movement of sand in response to wind is the most important feature of aeolian sediment transport on Earth and other planets. Through sand blasting during saltation, large amounts of dust are ejected into the atmosphere and transported long distances, impacting climate and human health. Despite continuing improvements, currently available devices for field measurement of sand movement have limitations.

An optical gate device (OGD) for detecting the movement, size, and possibly speed of individual sand grains during aeolian sediment transport was analyzed. The approach uses the highly time resolved signal from these sensors, which consist of a light emitter and a photosensitive sensor.

A specific OGD that is manufactured by Optek (Carrollton, Texas, USA) was tested in a sediment transport wind tunnel alongside trap-style devices. The OGD device provided particle counts and total signal response that were well correlated with sand trap data $\left(\mathrm{R}^{2}\right.$ between 0.66 and 0.88$)$. Intercomparison among eight identical units of the OGD showed excellent repeatability $\left(R^{2}>0.98\right.$ for 7 of 8 units). Subsequent tests revealed that the response of the phototransistor (light sensor) can be linear when operated within certain workable limits. Practical implications of this are that there is potential for extracting size distribution information. Limits imposed by noise levels in the signal and interferences from extraneous light sources were also identified.

Despite the results presented being specific to the OGD model tested, much of the approach outlined is applicable to any OGD-type device (including Wenglor ${ }^{\circledR}$ ) where the signal of the photodiode can be accessed directly.

Keywords: Saltation, Sand Flux, Dust Emissions, Wind Erosion, Mars 


\section{INTRODUCTION}

The transport of sand by wind along an erodible surface is perhaps the most critical physical manifestation of the wind erosion process in the context of both geomorphological development of certain landscapes (e.g., deserts, drylands, dunes, sandy coastlines, etc.) and the conditions necessary for the emission of large quantities of dust into the atmosphere. Here, sand is defined as particles or aggregates that have sizes that are well suited for aerodynamic entrainment by wind, corresponding in the terrestrial context to particle or aggregate diameters between 60 and $2000 \mu \mathrm{m}$. Dust (particles $<30 \mu \mathrm{m}$ in diameter) is operationally defined as material that can stay in suspension for long periods of time (minutes to weeks) and be transported over large distances (hundreds of meters to thousands of kilometers). So critical is this movement of sand, known as saltation, that nearly every field or wind tunnel study of wind erosion has used some device to measure the movement of sand as a primary indicator of the degree of erosion.

Several different types of measurement techniques for sand movement have been developed and used in the past. They range from technologically simple physical traps to advanced piezoelectric and optical sensors, each with an associated set of advantages and a set of drawbacks. There remains a need within the aeolian research community for an instrument platform that can provide a combination of a larger number of the desirable features of a sand sensor with fewer undesirable features. In this paper, we examine the use of a specific, simple optoelectronic sensor as a potential, next-generation sand movement sensor. Internal to our research group and to some collaborators, it has been referred to as the "Nikolich" sensor after the co-author that has most investigated its use in the capacity of a highly time-resolved movement sensor for detecting individual grains of sand in motion. The physical and electronic features of the sensor are described here and preliminary wind tunnel tests against traditional measurement techniques are summarized. A path for furtherance of the sensor based on technical challenges that need to be overcome is charted. The device described here is very similar to the more widely recognized Wenglor ${ }^{\circledR}$ sensor that has been reported by several previous investigators (Barchyn et al., 2014; Davidson- 
Arnott et al., 2009; Hugenholtz and Barchyn, 2011; Leonard and Cullather, 2008; Weaver and Wiggs, 2011). Although the Wenglor ${ }^{\circledR}$ was not the subject of the current work, it is discussed in the context of how the family of OGD sensors can be further developed and characterized to be more useful to the aeolian sediment transport research community.

\section{BACKGROUND}

Aeolian transport can be divided into bed load and suspended load. Bed load consists of creep, reptation, and saltation transport of the sand-sized particles. There are a number of important parameters that can be useful if measured when investigating transport in the bed load and those that are related to saltation are described here briefly. The saltation flux is generally measured through vertical integration of the horizontal transport in the dominant wind direction (units of mass per sediment per unit width per time). The often-invoked assumption of an exponential vertical profile may not be applicable to natural conditions where sediments are multi-sized and wind conditions are complex (e.g., Stout and Zobeck, 1996; Weinan et al., 1996), at least not as a rule. Shao (2005) uses similarity to argue that the flux is a "universal" function that depends on wind conditions as well as grain diameter and that under conditions of pure saltation, the function is an exponential decay with increasing height above the ground. This appears to be supported by wind tunnel (Dong and Qian, 2006; Xing, 2007) and field experiments (e.g., Gillies et al., 2013).

The size and speed of a sand particle in transport are important parameters, with direct influence on how energy gets transferred from the wind to the surface, which has been measured in few wind tunnel studies (e.g., Zhang et al., 2007) and fewer field studies (Greeley et al., 1996). Andreotti (2004) discusses two distinct distributions of moving sand grains. Saltons are high-energy (fast) grains that impact the surface and generally rebound as saltating particles, only occasionally becoming trapped by the surface. Reptons are dislodged when saltons impact the surface, but have low-energy (speed) and largely return to the surface, where they are trapped. Despite higher airborne concentrations of sand grains very near the 
surface, the horizontal flux is comparatively low near the surface due to low sand grain speeds there. This "redistribution/conservation" of sand grain energy has been observed in both field and wind tunnel tests (Butterfield, 1999; Mitha et al., 1986; Namikas, 2003; Zou et al., 2001), and is fundamental to understanding the saltation process, and is the cornerstone of several physical models (Anderson and Hallet, 1986; Sørensen, 2004; Ungar and Haff, 1987). To gain further understanding of the saltation process will require improvements in instrumentation to more accurately measure the vertical flux and the characteristics of the particles during transport.

Sediment transport by wind has been measured by a variety of instruments developed mainly to determine rates of transport, collect samples of the transported material, or investigate the temporal and spatial dynamics of sand movement. Accurately measuring these processes has been an ongoing challenge since the first known discrete measurements were made by Bagnold (1936). The instruments used since then vary in design and complexity but can be split into two categories: integrating and real-time electronic instruments. As shall be discussed, there have been incremental improvements in this latter category of devices that have been motivated, in part, by the observation that sediment transport occurs on spatial scales smaller than $0.2 \mathrm{~m}$ (Baas and Sherman, 2005) and temporal scales less than 1 second (Baas, 2006).

Integrating samplers have historically been the most common method for measuring the flux of sediment in field and laboratory investigations (Gillette et al., 1996; Nickling and McKenna Neuman, 1997; Ono et al., 2003). These devices can be defined as temporally averaged traps that sample the sediment-laden wind, retaining a portion of the sediment being moved by the wind. The general method of calculating the flux of sediment is through post-event collection and weighing of the trapped sediment. Advantages of this general design type are: retaining a sample for further analysis (chemistry and texture), ruggedness (can remain in the field for long periods of time), omni-directionality (points into the wind by a vane), and ability to collect sediment at multiple heights to obtain vertical integrals of transport (as 
opposed to single-height measurements). Initial designs were improved by increasing the efficiency through taking account of the aerodynamics associated with blocking a portion of the flow (Nickling and McKenna Neuman, 1997). Additional improvements were made by increasing the temporal resolution through automatic weighing systems (Jackson, 1996; Namikas, 2002) or by utilizing passive traps with impact-based devices to retroactively apply a temporal signature to the mass flux of sediment (Haustein et al., 2015). However, the spatial and temporal resolution of a mass-collecting sediment trap still remains insufficient for capturing most small-scale aeolian processes. In addition, because sand traps obstruct the flow to varying degrees, the efficiency of sampling saltating grains is variable with height and wind conditions ( $\mathrm{Li}$ and $\mathrm{Ni}, 2003$ ) but is generally around $80 \%$ (Goossens et al., 2000).

Impact-based devices have been the most popular real-time sensors since their first use by Gillette and Stockton (1989). The first widely available instrument was the SENSIT $^{\mathrm{TM}}$, which uses a piezoelectric crystal that registers the impact of sand grains through an exposed ring $\left(325 \mathrm{~mm}^{2}\right)$ around the cylindrical instrument. The Safire (Sabatech, Inc.) is a piezoelectric-based sensor that has been used in a variety of environments (Baas, 2004; Davidson-Arnott and Bauer, 2009; Gillies et al., 2013, 2006; Lancaster et al., 2010). The main advantage of the Safire is that it is less expensive than the SENSIT ${ }^{\mathrm{TM}}$, but several disadvantages have been documented (Sherman et al., 2011). In contrast, the Saltiphone (Jackson, 1996; Namikas, 2002; Poortinga et al., 2015; Rajot et al., 2003; Spaan and van den Abeele, 1991; Sterk et al., 1998; Visser et al., 2004) and Miniphone (Ellis et al., 2009) are better characterized devices. In general, impact sensors suffer from poor sensitivity to small sand grains (Van Pelt et al., 2009) and in the case of the Safire, poor inter-instrument repeatability (Baas, 2004).

Real-time Laser/CCD sensors have been used in laboratory experiments to capture sediment flux at one height at $25 \mathrm{~Hz}$ (Butterfield, 1999). Particle image velocimetry has also been used in laboratory wind tunnels to measure the sediment mass flux (Dong et al., 2006; O’Brien and McKenna Neuman, 2012). These methods have been restricted to the laboratory because of complicated setups, inherent 
disturbance of the surface, and costs. The sand particle counter (SPC, Mikami et al., 2005) uses a laserscattering technology to infer a 32-channel particle size distribution for particles with diameters from 30 to $667 \mu \mathrm{m}$. Although it was only recently introduced, the SPC has been used in Mongolia (Shinoda et al., 2011), Morocco (Kandler et al., 2009), Australia (Ishizuka et al., 2008), and China (Kurosaki and Mikami, 2007; Mikami, 2005).

An optical sensor manufactured by Wenglor $^{\circledR}$ has recently received considerable attention (Davidson-Arnott et al., 2009; Hugenholtz and Barchyn, 2011; Leonard and Cullather, 2008; Sherman et al., 2011). The sensor consists of a laser (655 nm wavelength) and a photosensor that are separated by 30 $\mathrm{mm}$. The blockage of light by a sand grain moving through the beam registers as a drop in the light signal reaching the photo-sensitive sensor and this is interpreted by onboard electronics as a pulse. This sensor is an example of an optical gate device (OGD). However, to our knowledge, the Wenglor ${ }^{\circledR}$ sensor has only been successfully used to measure particle counts and infer sediment fluxes through calibration with mass based traps (Barchyn et al., 2014; Martin et al., 2016), but not for the detailed examination of the timeseries signal associated with individual sand grains.

\section{METHODS}

The device described here and used to conduct analyses is also an optical gate device, one that is manufactured by Optek (Model OPB800W55Z, Carrollton, TX, USA, Figure 1). It is one of dozens of configurations of this type of device that are available from several manufacturers. This OGD was originally used experimentally while trying to identify an inexpensive indicator of sand motion in the PISWERL $^{\circledR}$ (Etyemezian et al., 2007; Sweeney et al., 2008), a field instrument for measuring wind erosion properties of soils. Early experimentation indicated that even when employing rudimentary signal processing, the device showed aptitude for both identifying the threshold for sand movement and providing a meaningful surrogate for the sand flux (Sweeney and Mason, 2013). It was clear that improved characterization of the OGD could lead to enhanced capability to interpret the sensor signal. It 
is anticipated that much of what is reported here for this specific OGD model can be applied to other models, including possibly the more widely recognized Wenglor ${ }^{\circledR}$ sensor (Hugenholtz and Barchyn, 2011; Sherman et al., 2011), provided that the "raw" signal from that device can be tapped into in a comparable manner to what has been done here. However, this specific model was selected for initial testing and it has been advantageous to continue using this model for the characterization that is described here. Therefore, unless otherwise specified, all data presented and references to "OGD" or "device" hereafter refer specifically to the Optek Model OPB800W55Z.

Broadly, two types of characterizations of the OGD were completed and are summarized here. First, the ability of the OGD signal to correlate with existing aggregate measures of sand flux was tested in a wind tunnel. Second, several pilot tests were conducted to reveal specific attributes of the sensor signal in response to varying conditions.

\subsection{Optek, Model OPB800W55Z description}

Referring to Figure 1, light $(\lambda=890 \mathrm{~nm}$ ) (i) is emitted from an infrared (IR) diode (emitter) (ii) goes through a wide-angle, hemispherical lens, (iii) passes through a $1.27 \mathrm{~mm} \times 1.27 \mathrm{~mm}$ square aperture, (iv) travels $9.53 \mathrm{~mm}$ across the "gate", (v) passes through a second $1.27 \mathrm{~mm} \times 1.27 \mathrm{~mm}$ square aperture, (vi) is collimated by a hemispherical lens that is integrated into the body of the phototransistor (sensor) device, and (vii) is translated by the phototransistor into an electrical signal. Plastic lenses that are essentially transparent are emplaced in front of the apertures on both the emitter and sensor sides and act as protective shields. Other than these two lenses that are on either side of the gate, the shell that holds the entire optical gate assembly together is opaque.

Electrically, the OGD itself has four terminals. Two supply power while the third is the return from the emitter and the fourth is the return from the sensor. Figure 2 shows an example of how the OGD can be connected to a $5-\mathrm{V}$ power supply. The rectangular box represents the sensor as provided by the manufacturer. A few simple modifications that require a basic background in electronics allow for some 
flexibility in how the sensor can be interfaced with standard signal measuring devices. Notably, in addition to the power supply, two resistors $\left(R_{1}\right.$ and $\left.R_{2}\right)$ must be soldered or otherwise connected electrically as shown in Figure 2.

Given that the voltage drop across the IR diode is roughly constant $(\approx 1.25 \mathrm{~V})$, when the diode is forward-biased, the emitter current and consequently the power output are dictated by the selection of the resistor $R_{1}\left(I_{D 1}=\left(V_{\text {in }}-V_{D 1}\right) / R_{1}\right.$ and $\left.P_{D 1}=V_{D 1} * I_{D 1}=V_{D 1}\left(V_{i n}-V_{D 1}\right) / R_{1}\right)$. A decrease in $R_{1}$ results in a very nearly proportional increase in light emitter power. A decrease in $\mathrm{R}_{2}$ results in a nearly proportional decrease in the voltage drop across $R_{2}$ (measured as $V_{R 2}$ ) when the phototransistor is biased to operate in the linear region. Within certain limits that will be discussed in the results section, varying these two resistors provides some flexibility for accommodating specific signal to noise criteria and input parameters for a range of analog to digital signal converters. As depicted in the figure, what is actually measured is the voltage $\mathrm{V}_{\mathrm{R} 2}$ relative to the ground.

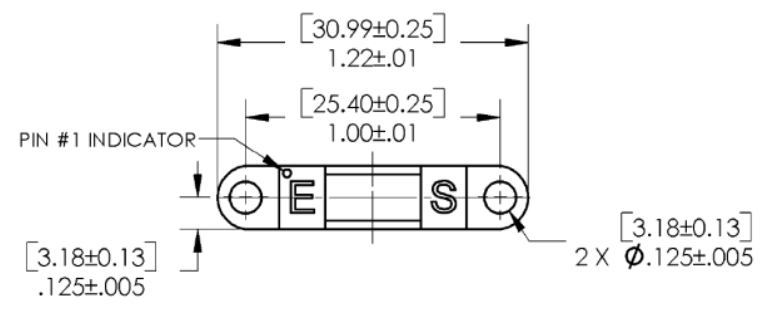

Top View

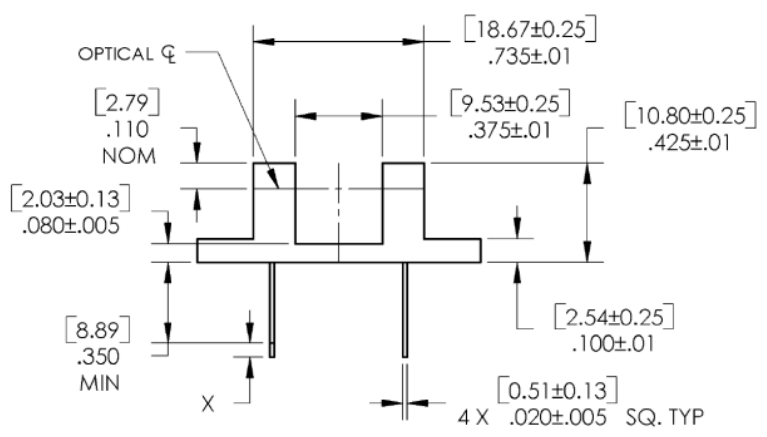

b. Side View

Figure 1. Schematic of Optek (model OPB800W55Z) optical gate device. All dimensions in mm. The light beam $(890 \mathrm{~nm})$ is $1.27 \mathrm{~mm}$-sided square in aperture. 


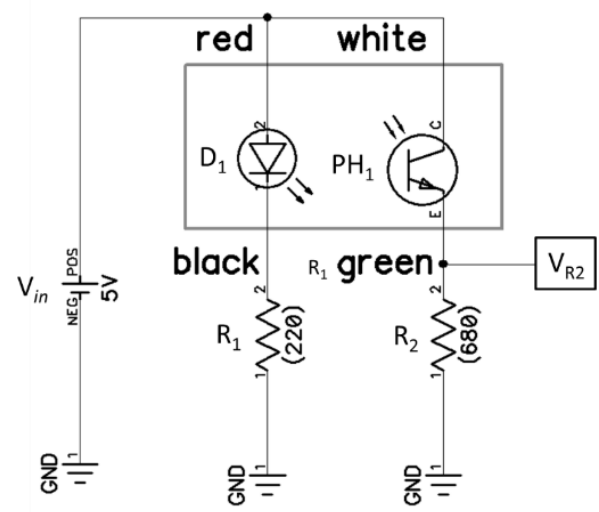

Figure 2. Example wiring diagram for OPB800W55Z connected to a $5 \mathrm{~V}$ power supply. Wire colors apply to the pre-wired "W" package. Choice of resistors $R 1$ and $R 2$ allows for varying power to emitter and $V_{R 2}$ linear range from phototransistor. The rectangular box represents the sensor as it comes from the supplier.

\subsection{Measuring aggregate sand flux}

A set of wind tunnel measurements was conducted at the University of Guelph sediment transport wind tunnel (Crawley and Nickling, 2003). The goal of the tests was to compare the performance of the OGD to a well-established slit trap sampler modified from earlier designs of Bagnold (1941) and Gillette (1977). The Nickling slit trap (NST) has a $10 \mathrm{~mm}$ wide by $25 \mathrm{~cm}$ high inlet orifice. Unlike earlier designs the majority of both side panels of the trap are covered with 230 mesh stainless steel screen $(70 \mathrm{~mm} \times 18$ $\mathrm{mm})$. This allows air pressure in the trap to dissipate, provides isokinetic flow conditions, and eliminates related sampling bias (Figure 3). Sand enters the NST and is funneled to an electronic balance (Metler, Model PL120) mounted in an air tight box located below the wind tunnel working section floor. The sand collected on the balance can be weighed at the end of an experiment (time averaged mass or flux) or in real-time in $0.1 \mathrm{~s}$ time intervals. This trap has been thoroughly tested using hot wire anemometry and pressure sensors inside and outside of the trap. The NST has also been tested against a wide range of other static and electronic traps and found to have superior collection efficiencies (nearly 100\%) in all cases. 

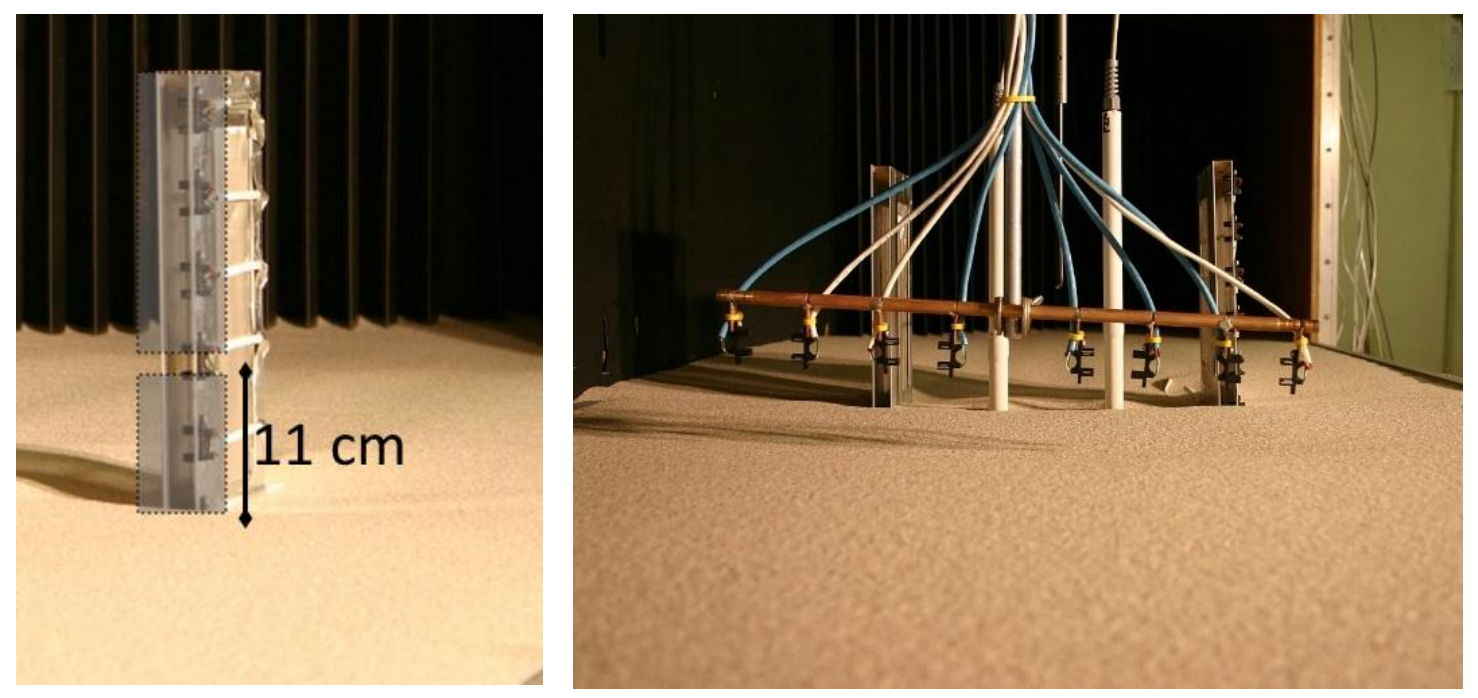

Figure 3. NST retrofitted with OGDs. Left: Trap is shown on a sand bed inside of the wind tunnel prior to a measurement run. Gray shading demonstrate where the trap was masked with aluminum tape for testing the $11 \mathrm{~cm}$ OGD. Right: OGDs mounted on a rake-type device in the foreground and two NSTs in background. Sensors are numbered sequentially from $1-8$ going from right to left.

The NSTs were retrofitted to hold OGDs at six different heights along the wedge opening in order to measure the signal from sand grains at multiple heights. Despite being mounted at six different heights along the NST, in practice, data were only collected for the OGD at a height of $4 \mathrm{~cm}$ and then again separately for the one at $11 \mathrm{~cm}$. In each case, the NST inlet slot was taped off with aluminum tape so that the only portion that was not blocked corresponded to the OGD opening. Empty NSTs were emplaced in the test section of the wind tunnel atop a graded sand bed (mean diameter $=340 \mu \mathrm{m}$ ) that extended $7 \mathrm{~m}$ upstream and $1 \mathrm{~m}$ downstream. Central placement of all instrumentation accounted for near-wall effects from the sides of the tunnel ensuring that the NSTs were sampling in the bulk flow region. Collection of electronic data was initiated at the same time that the fan in the wind tunnel was started, reaching steady state within $\approx 10 \mathrm{~s}$. Most tests lasted for $\approx 120 \mathrm{~s}$ with some variation if insufficient material was collected in the NST, resulting in extension of the test up to $\approx 600 \mathrm{~s}$ or when the sediment bed began exhibiting signs of depletion. The fan speed was varied over the range of $18-34 \mathrm{Hertz}(\mathrm{Hz})$, with $\mathrm{u}_{*}$ (estimated from wind speed profiles measured with Pitot-static tubes at multiple heights) ranging from $0.27 \mathrm{~m} \mathrm{~s}^{-1}$ to 
$0.62 \mathrm{~m} \mathrm{~s}^{-1}$.

In a separate test configuration, a series of eight OGDs was also connected to a post that ran parallel to the sediment bed, but perpendicular to the flow and elevated approximately $6 \mathrm{~cm}$ above the bed (see Right panel in Figure 3). These data were used to assess inter-sensor variability.

Data from the OGD being tested (either the one at $4 \mathrm{~cm}$ or the one at $11 \mathrm{~cm}$ ) were collected and logged to a file at $2 \mathrm{kHz}$ for the wind tunnel tests. The signal from the OGD sensors was scaled so that it could be accommodated by an 11-bit analog to digital converter over the full scale $(0-5 \mathrm{~V})$. The $2 \mathrm{kHz}$ signal was processed in real time to provide one-second measurement averages, which were subsequently stored.

Signal processing during wind tunnel testing was fairly simple. Figure 4 shows a time trace of the signal from a single OGD. Prior to the beginning of each test, a "baseline" voltage reading was obtained under conditions of no sand movement (red trace in the Figure). If the signal dipped below the baseline by a predetermined threshold value (determined to be $40 \mathrm{mV}$ in the case of the wind tunnel tests based on visual examination of signal noise levels), then the datum point and all ensuing data points that are above the threshold were assumed to correspond to the presence of a sand particle in the sensing volume of the OGD. This resulted in the incrementing of a particle counter and the incrementing of the "signal integral". The "signal area" at any point that was deemed to be associated with the presence of a particle was simply the difference between the instantaneous signal value and the baseline value. Therefore, for each instance when the signal crossed the threshold limit and returned below the threshold limit, the particle counter was incremented by one. In contrast the signal integral represented the sum of all baseline-corrected readings that correspond to the signal being below the threshold. The calculation of these entities and their relationship to the one-second particle counts and signal area totals are demonstrated in Figure 4. 


\subsection{Sensor characterization: Interpreting signals and interferences under field conditions}

In order to better understand how the OGDs can be expected to behave in real-world conditions, several pilot tests were conducted to target answers to specific questions. These tests were largely exploratory in nature and as such, detailed methods are not provided here. We state here briefly that OGDs were deployed in various configurations: 1) to determine how they behave under conditions of fluctuating outdoor illumination, 2) to ascertain the potential for the sensors to be used to infer size distributions of sand moving under the influence of wind, and 3) to gauge the limits of signal interpretation that are imposed by the physical configuration of the sensor. Where helpful, specific configurations of pilot tests are described alongside the presentation of results in the following section.

\section{RESULTS AND DISCUSSION}

Results from wind tunnel studies are presented in 4.1 with additional results of OGD performance provided in subsequent sections. The wind tunnel results provide assurance that if operated as a particle counter, the OGD described here could be a satisfactory device that is perhaps comparable to the Wenglor $^{\circledR}$. Analyses in subsequent sections are intended to delve into the details of how the time-resolved raw signal data from the OGD photodetector can be used to make particle count information more accurate and less prone to interferences and artifacts. As well, in the detailed analysis of what the OGD signal actually consists of, the possibility is examined of extracting other information such as particle size and speed. 


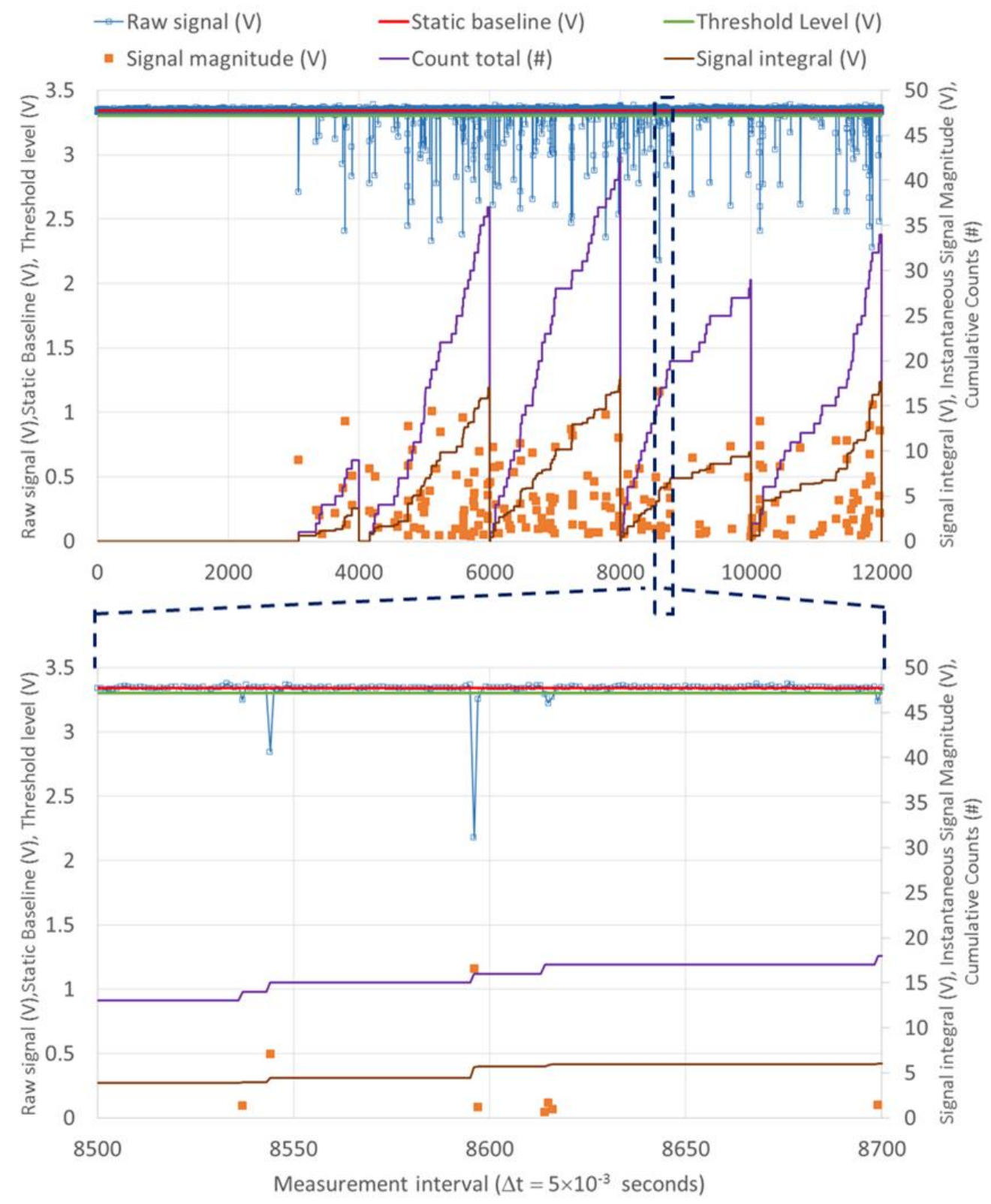

Figure 4. Example signal from OGD in wind tunnel studies on two temporal scales. Signal sampled at $2 \mathrm{kHz}$.

\subsection{Wind Tunnel Characterization}

Figure 5 shows the results of transverse collocation of eight OGDs in the wind tunnel. Data shown are minute-averaged one-second counts and signal integrals. The numbers correspond to the OGDs in the right panel of Figure 3, with the numbers increasing from right to left. Although both counts and the signal integral are shown in Figure 5, the two entities are actually very well correlated in this case, 
with linear regressions for seven out of the eight devices having $R^{2}(n=80)$ greater than 0.98 . This is likely because the portion of the signal that is associated with sand grain detection is very small (similar to the bottom panel of Figure 4), so that the difference between the counts of the signal crossing the threshold and the integral of the signal with respect to the baseline is a constant multiple despite the two quantities relaying somewhat different pieces of information. The correlation between different devices is also quite high. When linear regressions are performed between the counts from the first OGD and those from any of the seven others, $\mathrm{R}^{2}$ values are higher than 0.98 for almost all devices (except for OGD \#2, which exhibits two peaks at the $95^{\text {th }}$ and $110^{\text {th }}$ second that other devices do not record). Signal integrals among devices have equal or greater $\mathrm{R}^{2}$ values compared to counts (including for OGS \#2). Differences in absolute magnitudes of counts and signal integral among devices are a result, at least in part, of an imperfect instrument setup during these preliminary tests (Note that sensors are on a tilt with respect to the test bed in Figure 3 and that sensor \#1 is closer to the bed than sensor \#8).

The OGDs compare well with the mass-based NST measurements that were collected during wind tunnel tests. Figure 6 shows comparisons of counts and signal integral values that were collected using the simple threshold algorithm, with mass based measurements of sand that were coincident with openings in the trap (correspond to heights of $4 \mathrm{~cm}$ and $11 \mathrm{~cm}$ ). Both counts and signal integral values show that a linear relationship can explain a good amount of the variance with $\mathrm{R}^{2}$ ranging from 0.66 to 0.88 for the different combinations of OGDs and metric used (counts versus signal integral). 


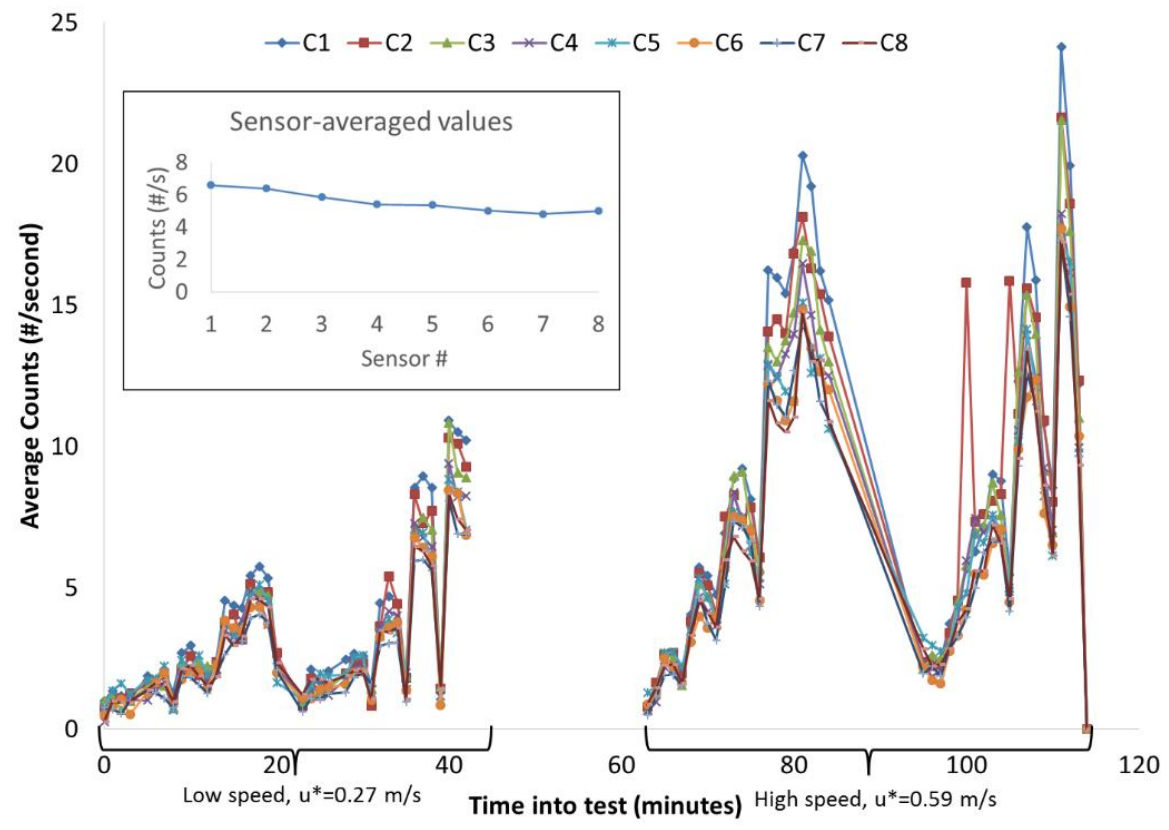

a. counts

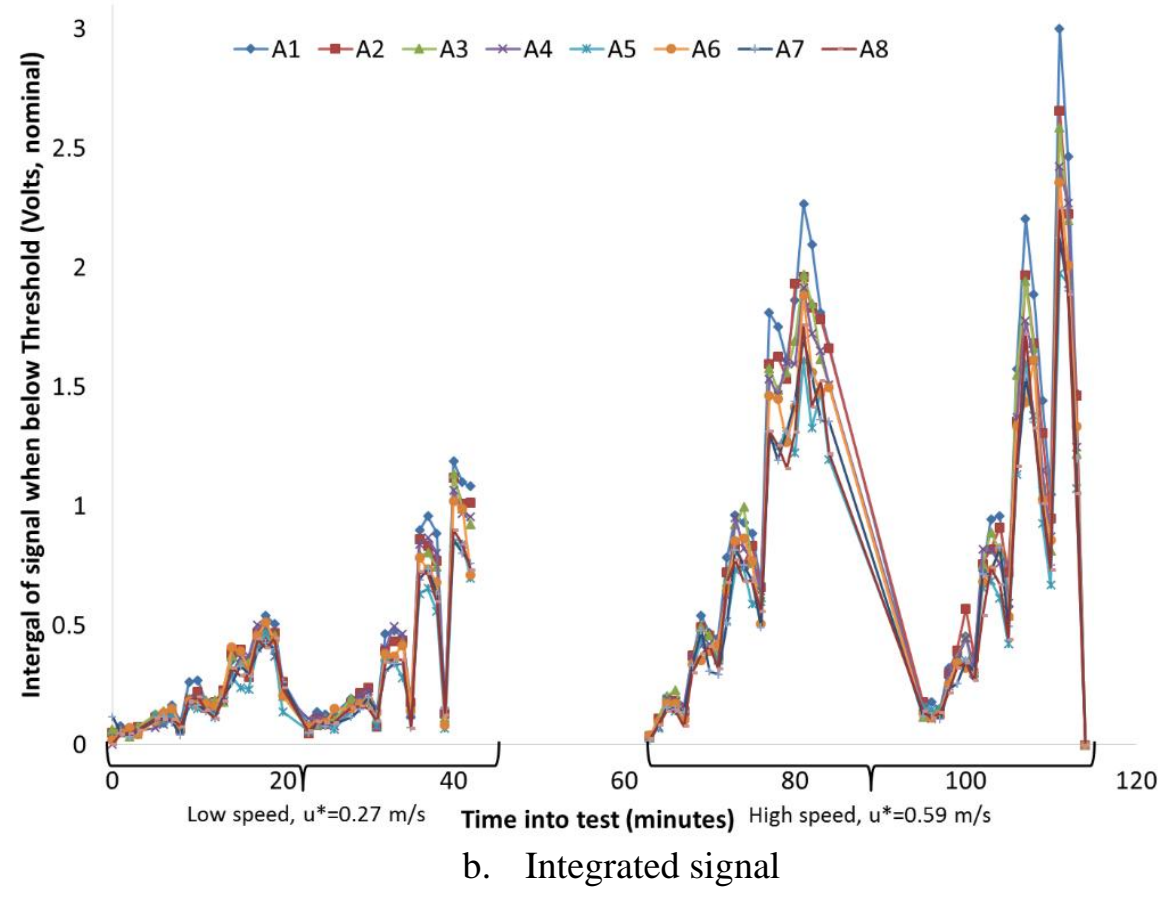

Figure 5. Minute-by-minute averages of one-second counts and signal area for 8, transverse-collocated OGDs. Sensor 1 corresponds to the rightmost sensor in the right hand panel of Figure 3 and sensor 8 corresponds to the left most sensor. 
The relationship between measured mass and the OGD parameters (either count or signal integral) appear to be quite different between the unit at the $4 \mathrm{~cm}$ height and the one at the $11 \mathrm{~cm}$ height. For comparable amounts of mass, the counts and signal integral values from the OGDs are smaller for the data collected at the higher open section of the NST. The relationship between count and signal integral (panel c of Figure 6) does not appear to be as influenced by the device height, suggesting that the distribution of the magnitudes of the signal normalized to the counts are similar at the two heights. On balance, these observations indicate that the OGDs were less efficient at detecting particles at the $11 \mathrm{~cm}$ height than at the $4 \mathrm{~cm}$ height. The reason for this is unknown at this time. It could be an aerodynamic effect, where fluid forces result in relatively fewer sand grains going through the active portion of the optical gate (where the light beam is crossing) and relatively greater numbers going through the inactive portion of the gate. Alternatively, this could be a result of sand particle speed effects. It is reasonable to expect that particles at $11 \mathrm{~cm}$ are traveling at different speeds than those at $4 \mathrm{~cm}$ height. It may be that the relatively slow sample rate $(2 \mathrm{kHz})$ resulted in sand particles that traveled through the active portion of the optical gate but traversed the illumination zone in between sample times. This is a plausible explanation because a $2 \mathrm{kHz}$ sample rate translates into a $0.0005 \mathrm{~s}(0.5 \mathrm{~ms})$ sample interval. A sand particle traveling across the $1.27 \mathrm{~mm}$ aperture in between sample points would have to be traveling at least $2.54 \mathrm{~m} / \mathrm{s}$, which is easily achieved by the wind speeds through the wind tunnel test section at those heights. In any case, it is important to consider that the "detection efficiency" of the OGD not be taken as static since there may be wind speed related phenomena that affect it, whether through changes in air flow patterns around the sensor or simply because of limitations of sample rate. We do note that in more recent experimentation with OGDs, the sample rate has been increased to $10 \mathrm{kHz}$. This should ameliorate the potential for particle speed related changes in detection efficiency, but this assertion has not yet been tested in a wind tunnel. 


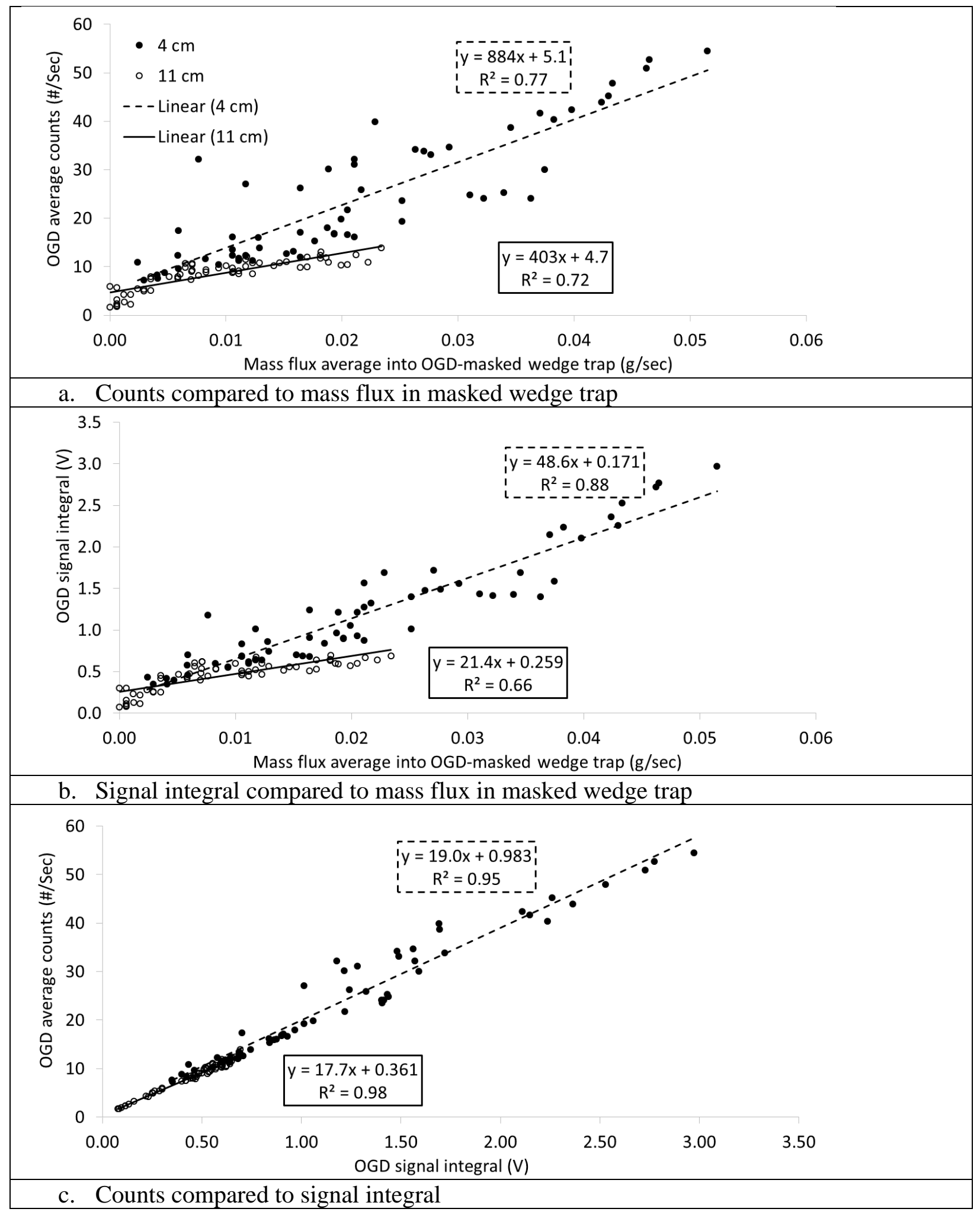

Figure 6. OGD counts, signal integral, and mass measurements from masked NST for two heights (n=60 for 4 $\mathrm{cm}$ high opening in wedge trap and $\mathrm{n}=60$ for $11 \mathrm{~cm}$ high opening). 
The collected data that were discussed in the prior section confirm that the OGD tested here has the potential to be a useful tool because it exhibits repeatability among units and accuracy (once calibrated) if we consider the mass-based NST as a standard for comparison. However, the wind tunnel measurements were collected under ideal, controlled conditions. If OGDs are to be used regularly as field deployable sand transport measurement devices, then the potential effects of departing from the ideal conditions of the laboratory wind tunnel must be considered.

\subsection{Signal, noise, and linearity}

Table 1 lists the wind tunnel testing conditions and provides some insight on how field use of these type of sampling devices may depart from ideality. It can be seen from examination of the table that a critical characteristic of OGDs is a linear sensor response for changes in incident light. Without such linearity, interpretation of the sensor signal can become quite difficult. Fortunately, there are two separate pieces of information that provide reassurance for the specific model used here (Optek, Model OPB800W55Z).

First, in a series of laboratory tests, the current $\left(I_{D 1}\right)$ through the IR diode $\left(D_{1}\right.$ in Figure 2$)$ was varied while the total voltage across the phototransistor (sensor) and $\mathrm{R}_{2}$ was kept constant at 5.0 V. This was repeated for several different values of resistance $R_{2}$ and the results are shown in Figure 7. For the photodiode, the power output (intensity of light emitted) varies linearly with the current $\mathrm{I}_{\mathrm{D} 1}$. When not saturated, the phototransistor is also expected to exhibit linear behavior, with current $\mathrm{I}_{\mathrm{ph} 1}$ being proportional to the number of photons incident on the photosensitive component. The behavior of the phototransistor is governed by the equations:

$V_{\text {in }}=V_{C E}+V_{R 2}=5 \mathrm{~V}$

$V_{R 2}=I_{P H 1} \times R_{2}=h f e \times I_{b} \times R_{2}=I_{D 1} \times C T R \times R_{2}$ 
Table 1. Parameters that affect data quality from OGD-type sensors, potential tests for their impact, and options to ameliorate shortcomings.

\begin{tabular}{|c|c|c|c|}
\hline $\begin{array}{l}\text { Parameter/ } \\
\text { Condition }\end{array}$ & Wind tunnel condition & Potential field condition & $\begin{array}{l}\text { Potential means to address shortcoming/ Test to determine if } \\
\text { effective }\end{array}$ \\
\hline $\begin{array}{l}\text { 1. Initial full- } \\
\text { scale response }\end{array}$ & $\begin{array}{l}\text { All OGD sensors tested } \\
\text { selected to provide full scale } \\
\text { response of about } 3.5 \mathrm{~V} \text {. } \\
\text { Applying an absolute threshold } \\
\text { for peak detection results in } \\
\text { comparable sensitivity among } \\
\text { sensors }\end{array}$ & $\begin{array}{l}\text { OGD sensor response intensity } \\
\text { varies substantially from unit to unit. } \\
\text { This can result in signals from two } \\
\text { different units being different under } \\
\text { the same sand transport conditions }\end{array}$ & $\begin{array}{l}\text { Test: Linearity of sensor in response to linear changes in light } \\
\text { intensity } \\
\text { Fix: Normalize the signal to full-scale of specific unit's response } \\
\text { intensity and use normalized signal in place of raw signal to detect } \\
\text { sand grains. This requires that the light detector response be linear } \\
\text { with light intensity from emitter }\end{array}$ \\
\hline $\begin{array}{l}\text { 2. Degraded } \\
\text { full-scale } \\
\text { response }\end{array}$ & $\begin{array}{l}\text { All OGD were new and used } \\
\text { for relatively short periods of } \\
\text { time so that changes in full- } \\
\text { scale response were } \\
\text { undetectable over the course of } \\
\text { experiments }\end{array}$ & $\begin{array}{l}\text { OGD in the field will be subjected to } \\
\text { accumulation of dust and other } \\
\text { obscurants on emitter and sensor } \\
\text { lenses as well as abrasion of lenses } \\
\text { by sand bombardment }\end{array}$ & $\begin{array}{l}\text { Test: Comparability of "aged" sensors and "fresh" OGDs when } \\
\text { subjected to identical sand transport conditions. Likely a wind } \\
\text { tunnel exercise. } \\
\text { Fix: Normalize the signal to current full scale, recognizing that full- } \\
\text { scale for a given unit will change over time. }\end{array}$ \\
\hline $\begin{array}{l}\text { 3. Temperature } \\
\text { dependence }\end{array}$ & $\begin{array}{l}\text { Temperature controlled over } \\
\text { testing period }\end{array}$ & Ambient temperatures fluctuate & $\begin{array}{l}\text { Test: Linearity of sensor response to linear changes in light } \\
\text { intensity } \\
\text { Fix: Normalize the signal to current full-scale signal. }\end{array}$ \\
\hline $\begin{array}{l}\text { 4. Interferences: } \\
\text { Baseline shift }\end{array}$ & $\begin{array}{l}\text { Indoor room, stationary } \\
\text { sensors, minimal stray light }\end{array}$ & $\begin{array}{l}\text { Outdoor field deployment with } \\
\text { fluctuating diffuse ambient light and } \\
\text { direct light from sun and other } \\
\text { sources }\end{array}$ & $\begin{array}{l}\text { Test 1: Linearity of sensor response to linear changes in light } \\
\text { intensity } \\
\text { Test 2: Saturation potential for sensor under given lighting } \\
\text { conditions } \\
\text { Fix: Correct signal and normalization for stray light from other } \\
\text { sources. Use "dark signal" }\end{array}$ \\
\hline $\begin{array}{l}\text { 5. Interferences: } \\
\text { False counts }\end{array}$ & $\begin{array}{l}\text { Indoor room, stationary } \\
\text { sensors, minimal stray light } \\
\text { resulting in minimal false } \\
\text { counts. }\end{array}$ & $\begin{array}{l}\text { Direct light interference from sun or } \\
\text { other strong source could result in } \\
\text { false counts }\end{array}$ & $\begin{array}{l}\text { Test: Linearity of sensor response to linear changes in light } \\
\text { intensity } \\
\text { Fix [possible]: Correct counts with estimate of false counts using } \\
\text { "dark signal" }\end{array}$ \\
\hline $\begin{array}{l}\text { 6. Response } \\
\text { time }\end{array}$ & $2 \mathrm{kHz}$ sampling & $\begin{array}{l}10 \mathrm{kHz} \text { sampling, light source } \\
\text { switching }\end{array}$ & $\begin{array}{l}\text { Test: Speed of response of sensor to changes in light intensity } \\
\text { Fix: None suggested at this time }\end{array}$ \\
\hline $\begin{array}{l}\text { 7. Signal to } \\
\text { noise }\end{array}$ & Indoor-type electronic noise & $\begin{array}{l}\text { Outdoor-type electronic noise and } \\
\text { field rated electronics }\end{array}$ & $\begin{array}{l}\text { Test: field test for noise measurement } \\
\text { Fix: Collect and retain noise estimating parameters }\end{array}$ \\
\hline $\begin{array}{l}\text { 8. Sensor [sand } \\
\text { count] } \\
\text { saturation }\end{array}$ & $\begin{array}{l}\text { Sensor operated under } \\
\text { conditions far from saturation }\end{array}$ & $\begin{array}{l}\text { Real-world conditions can result in } \\
\text { individual sand grain signatures } \\
\text { overlapping to considerable degree }\end{array}$ & $\begin{array}{l}\text { Test: Estimate particle count level that results in saturation effects } \\
\text { Fix: Apply saturation correction, use integrated signal instead of } \\
\text { counts, use sensor with smaller gate gap }\end{array}$ \\
\hline
\end{tabular}




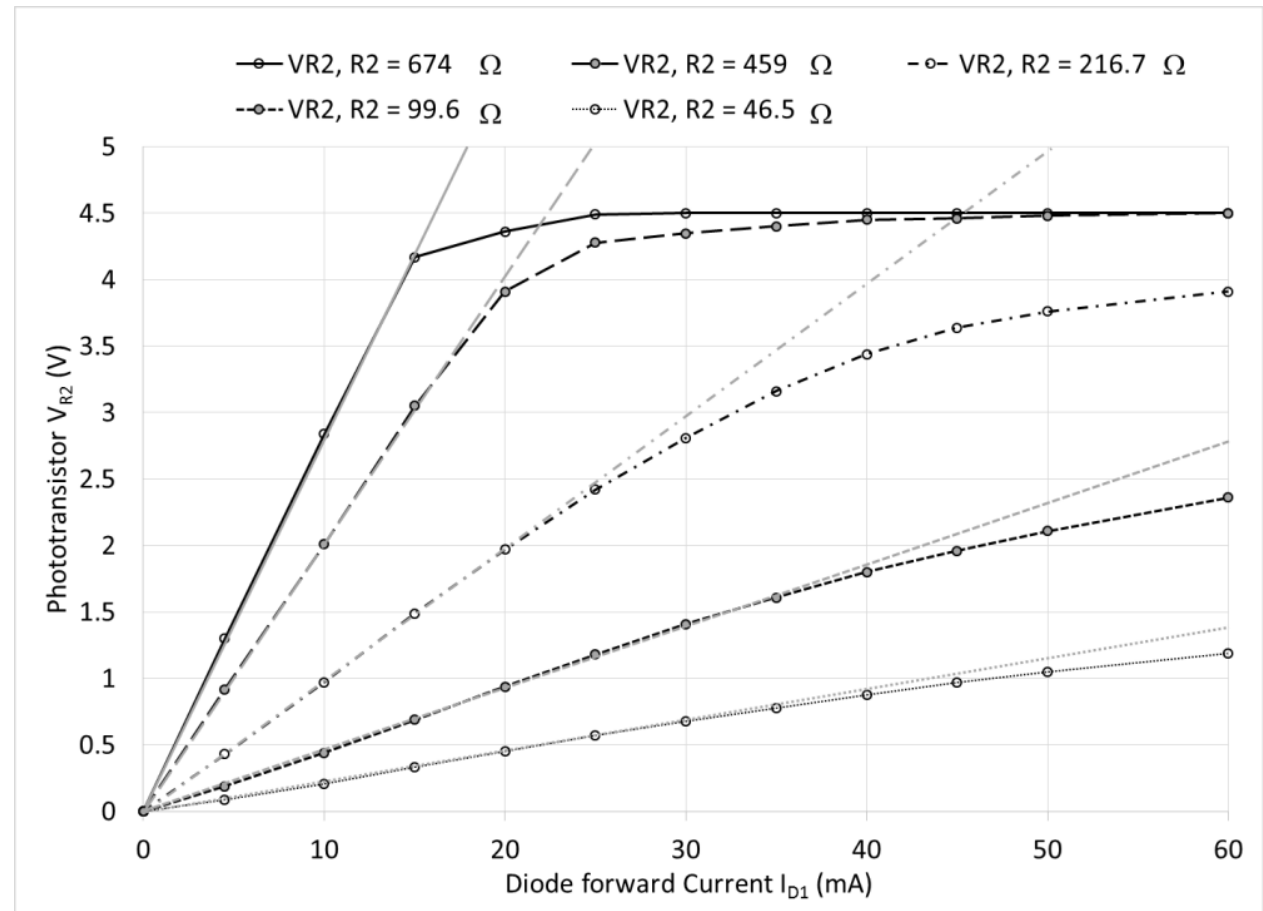

Figure 7. $V_{R 2}$ measured in response to variable amount of diode power (shown as current $I_{D 1}$ ) at different values of the resistor $\mathbf{R}_{2}$.

where Vin is the power supply voltage, $V C E$ is the collector-emitter voltage drop, $\mathrm{I}_{\mathrm{PH} 1}$ is the current through the phototransistor (and resistor $\mathrm{R}_{2}$ ), hfe is a "constant" of the phototransistor that relates the gate current $I_{b}$ to the current through the resistor $R_{2}, V_{R 2}$ is the basis for the signal from the sensor and is defined as the voltage drop across resistor $\mathrm{R}_{2}$, and CTR (current transfer ratio) is a constant that relates the number of photons per unit time that are incident on the phototransistor sensing component to the resultant gate current. Note that $\mathrm{V}_{\mathrm{CE}}$ must be above about $0.5 \mathrm{~V}$ in order to maintain the phototransistor below saturation. From Equation 1, it is clear that $V_{R 2}$ cannot exceed about 4.5 V. Below this value, the voltage $V_{R 2}$ is expected to vary linearly with the number of photons that are incident on the photosensitive component. This linear behavior can be seen from the curves shown in Figure 7 for different values of $R_{2}$. At the two highest values of $\mathrm{R}_{2}(459 \Omega$ and $674 \Omega), \mathrm{V}_{\mathrm{R} 2}$ responds linearly to changes in diode current up to about $15 \mathrm{~mA}$, thereafter the limitation on $\mathrm{V}_{\mathrm{R} 2}$ imposed by Equation 2 becomes evident. At lower values of $\mathrm{R}_{2}$ (46.5 $\Omega, 99.6 \Omega$, and $216.7 \Omega$ ), linearity extends to higher values of diode current (about 25 - 35 $\mathrm{mA}$ ). 
One pertinent point to glean from these observations is that in terms of light intensity changes, the phototransistor exhibits a linear response from zero to some upper limit that is dictated in part by the choice of the voltage $V_{\text {in }}$ and the resistance $R_{2}$. The second pertinent point is that even when the voltage $\mathrm{V}_{\mathrm{R} 2}$ is far from its maximum realizable value $(4.5 \mathrm{~V})$ based on semiconductor saturation considerations (i.e., saturation of $\mathrm{V}_{\mathrm{CE}}$ in Figure 2), the phototransistor begins to exhibit signs of nonlinear response at higher levels of light intensity. This can be seen most clearly for the lowest resistances (46.5 $\Omega$ and 99.6 $\Omega$ ) tested in Figure 7. At these higher values of light intensity (corresponding to about $I_{D 1}=35 \mathrm{~mA}$ ), the value of $h f e$ deviates from constant and begins to decrease. In practice, $h f e$ is also dependent on the voltage across the phototransistor $\mathrm{V}_{\mathrm{CE}}$.

Additional supporting evidence for linear behavior of the Optek OGD is provided in the product data sheet. There, the manufacturer provides results from blockage testing of the apertures, whereby an opaque, rectangular "flag" is used to block the light beam that goes from the emitter to the sensor. Illustrative portions of that information have been reproduced in Figure 8. Results are nearly identical for the flag blocking the beam from the right to the left whether the flag is close to the light emitter or close to the light sensor. Moreover, the relationship between the signal from the sensor and the distance between the edge of the flag and the beam centerline is linear. By itself, this suggests that the light beam is fairly spatially homogeneous across the aperture of the emitter and the sensor. However, when blocking the light from left to right, the response is not linear. Moreover, when blocking the light with a flag midway between the emitter and the sensor, the response is linear, but the apparent aperture of the beam is $\approx 20 \%$ smaller than when the flag is placed close to either the sensor or the emitter side. If this were only true for the flag traveling from the top of the sensor to the bottom, then one might expect that the effective aperture in the up-down direction is smaller than in the left-right direction. However, according to the data sheet, this same effect can be seen for travel from left to right and right to left. The exact reasons for these apparent discrepancies is not known. However, a plausible scenario is that the data 
shown by the manufacturer were not collected from the same unit, but rather from several different test units of the same model. If this is true, then the implication is that there are unit to unit variations that may have a potential impact on the quality of the measurement if they are not well characterized. It is important therefore that careful testing of these types of properties of individual sensors should be conducted on a substantial number of units from different batches to either determine that unit to unit variations are acceptable or to be able to define unit-specific correction parameters. An additional, related characteristic that should be investigated is the sensor response when the sensor is physically strained in different ways (stretched, twisted, bent, etc.). With the caveat that additional testing is needed, we proceed here with the assumption that either the sensor can be treated as a perfect optical gate with a spatially homogeneous light beam and linear response to light blockage or that corrections can be applied to mitigate significant deviations from this assumption at a future time.

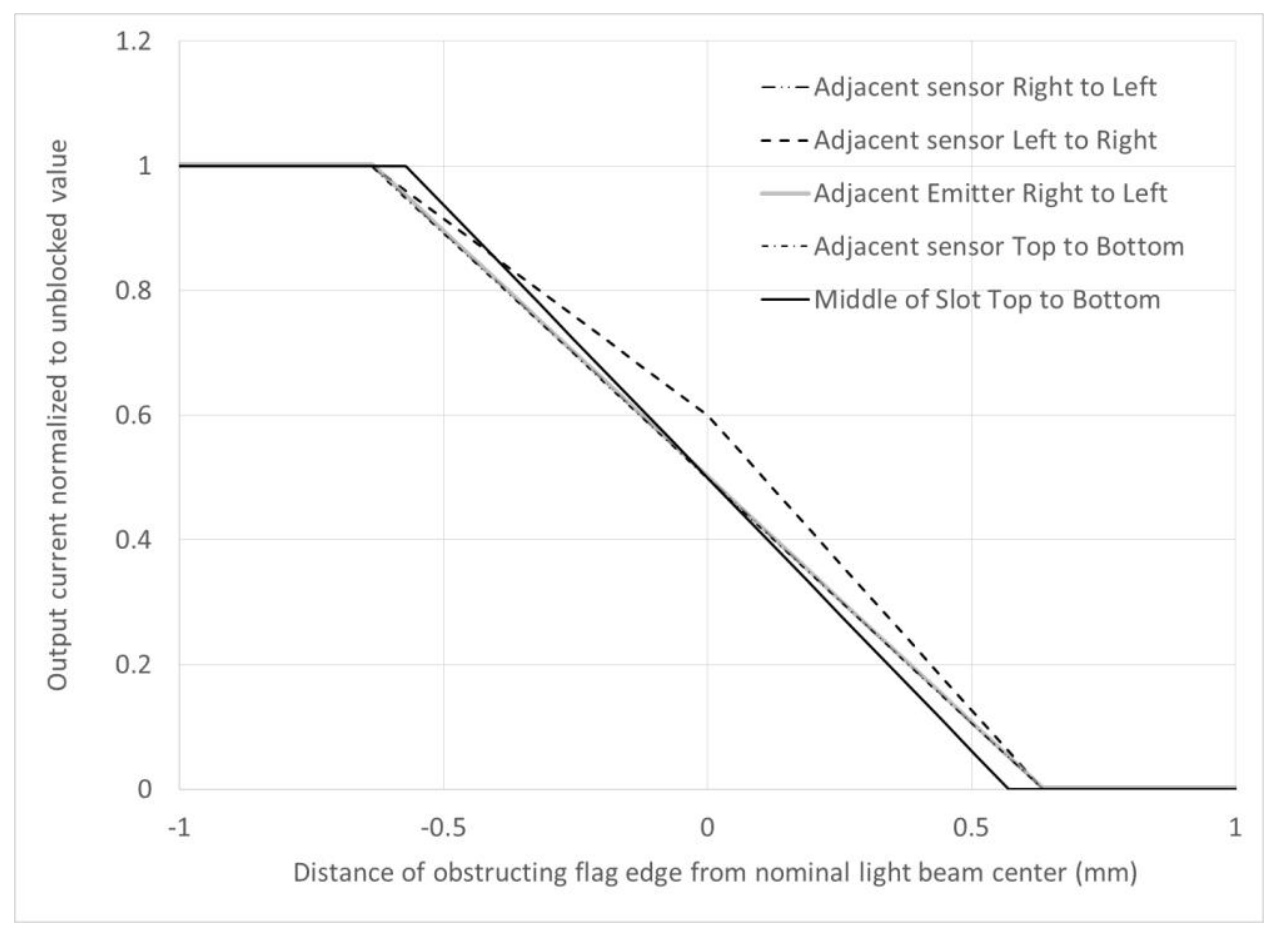

Figure 8. Optek OPB800W55Z response to partial blockage with solid flag. Data are shown for flag inserted adjacent to the phototransistor side from left to right, right to left, and top to bottom; adjacent to infrared diode (emitter) from right to left; and midpoint between the photodiode and phototransistor from top to bottom. Adapted from page 5 of Optek OPB800W55Z data specification sheet, Optek Technology, Inc. (issue B, 02/2013). 
With the above working assumption, the signal caused by blockage of light due to a sand-grain sized particle going through the gate at time $t$ is given by:

$V_{R 2}(t)=\left(1-\frac{A_{\text {block }}}{A_{\text {beam }}}\right) \times V_{R 2_{\text {base }}}(t)+\varepsilon(t)$

Where $A_{\text {block }}$ corresponds to the projected area of the sand grain in the direction of the light beam that spans the optical gate, $A_{\text {beam }}$ is the cross-sectional area of the light beam, $V_{R 2 b a s e}$ is the average baseline signal (voltage) that is a result of the emitter beam (i.e., in an otherwise dark setting) in the absence of a particle, and $\varepsilon$ represents essentially random noise in the signal (average over time is equal to zero). Assuming that the light beam has a square cross section with $1.27 \mathrm{~mm}$ sides (inferred from data sheet), $A_{\text {beam }}$ for the Optek OPB800W55Z is $1.61 \mathrm{~mm}^{2}$, and that the particle obstructing the light beam is spherical with diameter $D_{i}$ and fully immersed in the beam so that $A_{\text {block }}$ can be equated to $\pi D_{i}^{2} / 4$, the particle diameter can be related to the measured signal with the equation:

$D_{i}=\sqrt{\frac{4}{\pi}\left(1-\frac{V_{R 2}(t)-\varepsilon(t)}{V_{R 2_{\text {base }}}(t)}\right) \times 1.61 \mathrm{~mm}^{2}}$

Ideally, the random noise in the signal is quite small compared to the magnitude of the signal (i.e., $\mathrm{V}_{\mathrm{R} 2 \text { base }}-\mathrm{V}_{\mathrm{R} 2}>>\varepsilon$ ), but this depends on the size of the particle blocking the beam. In practice, only the standard deviation of $\varepsilon\left(\sigma_{\varepsilon}\right)$ can be estimated from measurement of the fluctuation of the signal in the absence of any particles blocking the beam. Assuming for convenience that $\varepsilon$ is normally distributed, then some multiple $(\mathrm{K})$ of $\sigma_{\varepsilon}$ can be used as a threshold value for determining if a measurement at time $\mathrm{t}$ is associated with a particle or with signal noise according to the rule: 


$$
\left\{\begin{aligned}
\text { Particle with } D_{i}= & \left.\sqrt{\frac{4}{\pi}\left(1-\frac{V_{R 2}(t)}{V_{R 2} \text { base }}(t)\right.}\right) \times 1.61 m m^{2} I F V_{R 2_{\text {base }}}(t)-V_{R 2}(t)>\mathrm{K} \sigma_{\varepsilon} \\
& \text { Not a particle IF } V_{R 2_{\text {base }}}(t)-V_{R 2}(t) \leq \mathrm{K} \sigma_{\varepsilon}
\end{aligned}\right.
$$

Equation 5 offers a simple way to deal with extracting information from a noisy signal. There are many other techniques to deal with noise, with some undoubtedly better at exploiting the properties of the noise distribution to maximize the information that can be extracted from the signal. Nevertheless, it is useful to note that, $\sigma_{\varepsilon}$ has been as low as about $0.002 \mathrm{~V}$ (estimated by taking the standard deviation of the signal over several seconds in the complete absence of particles) under ideal laboratory conditions and more like $0.006 \mathrm{~V}$ under field conditions with $\mathrm{V}_{\mathrm{R} 2 \mathrm{base}}$ values of about $4.5 \mathrm{~V}$. Taking the noise threshold to be three standard deviations of the noise signal (i.e., setting $\mathrm{K}$ to 3 ), corresponds to equivalent particle diameters of 52 micrometers and 90 micrometers under lab and field conditions, respectively. These can be thought of as practical lower limits on the sizes of particles that can be detected. It is unknown how low these noise levels can be reduced if electronics are optimized for noise abatement and the devices used to convert the analog signal from the sensor to a digitized signal have high resolution. We conjecture here that noise levels can be improved by about a factor of 2 for field conditions allowing the detection of particles as small as $65 \mu \mathrm{m}$ (diameter) using the criteria of Equation 5. Perhaps more sophisticated treatment of noise can further reduce the lowest size of sediment grain that is practically detectable.

The above discussion has two important implications. First, the OGD is responsive to particles that are of greatest importance with respect to aeolian saltation processes, namely those that are roughly $60 \mu \mathrm{m}$ in size and larger. Second, the sensor will not register the presence of small, dust-sized particles in the sensing volume as distinct, individual particles since their individual signals are much smaller than the noise levels. Instead, the presence of small particles will be reflected in a change in the apparent baseline signal $\mathrm{V}_{\mathrm{R} 2 \mathrm{base}}$. The consequence of this is that the presence of dust particles in the air will not substantially impact the ability of the OGD to identify the presence of larger sand-sized grains unless the presence of 
dust adds noise and increases substantially $\sigma_{\varepsilon}$. Although the degree to which the baseline signal $\mathrm{V}_{\mathrm{R} 2 \mathrm{base}}$ is decreased by the presence of dust depends greatly on the size distribution of dust particles, as a point of reference, consider that concentrations on the order of $1 \mathrm{~g} / \mathrm{m}^{3}$, which are extremely high and assuming a mass absorption and scattering efficiency on the order of $10 \mathrm{~m}^{2} / \mathrm{g}$ (also quite high), according to Boguer's law, dust is not likely to decrease the baseline signal by more than about $50 \%$ of its initial, non-dusty value. In this simplified analysis, complexities added by the scattering due to small particles, which has the effect of changing the effective shape of the light beam are not considered, but it is anticipated that they are secondary to the main effect of reducing the amount of light that travels from the emitter to the sensor.

\subsection{Influence of environment conditions on sensor performance}

Under typical field conditions, external light from surfaces that reflect direct sunlight or ambient, diffuse sunlight does have the potential to impact the interpretation of the signal from the OGD. In the simplest case, light that is incident on the sensor but that did not originate from the emitter would only have the effect of modifying Equation 3 so that the revised equation would be:

$V_{R 2}(t)=\left(1-\frac{A_{\text {block }}}{A_{\text {beam }}}\right) \times V_{R 2_{\text {base }}}(t)+\varepsilon(t)+V_{\text {ambient }}(t)$

where the new term $\mathrm{V}_{\text {ambient }}$ reflects an additive signal that is the resultant of all ambient light that does not originate at the emitter. This then impacts Equation 5 so that the revised form corrects for a shift in baseline caused by ambient light according to:

$$
\left\{\begin{array}{c}
D_{i}=\sqrt{\frac{4}{\pi}\left(1-\frac{V_{R 2}(t)-V_{\text {ambient }}(t)}{V_{R 2_{\text {base }}}(t)}\right) \times 1.61 m m^{2}} \text { IF } V_{R 2_{\text {base }}}(t)-\left[V_{R 2}(t)-V_{\text {ambient }}(t)\right]>\mathrm{K} \sigma_{\varepsilon} \\
\text { Not a particle IF } V_{R 2_{\text {base }}}(t)-\left[V_{R 2}(t)-V_{\text {ambient }}(t)\right] \leq \mathrm{K} \sigma_{\varepsilon}
\end{array}\right.
$$

In practice, the introduction of ambient light into the system has several complicating implications. First, as noted previously, the phototransistor has an upper limit of linearity, above which 
hfe in Equation 3 is no longer constant. At high enough values of light intensity, the phototransistor can become totally saturated so that additional light does not result in any additional signal. It is not known what level of light intensity causes this saturation, but it is known that direct sunlight onto the sensor is sufficient. While operating in the nonlinear region can make the interpretation of the signal more difficult, light saturation of the sensor totally invalidates the measurement. Therefore, as a practical matter, to the extent possible OGDs should be oriented to avoid direct or reflected sunlight and preferably so that the incremental signal from ambient light is small enough that the sensor continues to operate in the linear regime.

A second practical problem is that in order to apply Equation 6, the value of $\mathrm{V}_{\text {ambient }}(\mathrm{t})$ must be known because $\mathrm{V}_{\mathrm{R} 2 \mathrm{base}}$ is not constant and can change over time for a number of reasons and over a number of timescales. These include temperature changes that impact both the IR diode emitter and the phototransistor sensor, changes in supply voltage to the OGD, changes in ambient dust levels, and possible changes in the clarity of the lenses that protect the emitter and the sensor. Consequently, both $V_{R 2}(t)$ and $V_{\text {ambient }}(t)$ vary in time. If the OGD is mounted on a platform that rotates so that the sensor is always oriented in a specific direction with respect to the wind, the timescales for changes in $\mathrm{V}_{\text {ambient }}(\mathrm{t})$ could be on the order of $0.1 \mathrm{~s}$ depending on how quickly the platform responds to changes in wind direction. One method to estimate the value of $\mathrm{V}_{\text {ambient }}(\mathrm{t})$ is to measure $\mathrm{V}_{\mathrm{R} 2}$ when the photodiode is completely off so that $\mathrm{V}_{\mathrm{R} 2 \text { base }}$ is by definition equal to zero and Equation 6 becomes:

$V_{R 2}(t)_{\text {diode_off }}=V_{\text {ambient }}(t)$

Under these conditions, the value of $\mathrm{V}_{\mathrm{R} 2}$ can be considered the "dark [diode] signal". Once the IR diode is turned back on again, an estimate of $\mathrm{V}_{\text {ambient }}(t)$ can be taken to be $\mathrm{V}_{\text {ambient }}\left(\mathrm{T}_{\mathrm{j}}\right)$ where $\mathrm{T}_{\mathrm{j}}$ represents the $\mathrm{j}^{\text {th }}$ interval of duration $\mathrm{T}$ when the photodiode was off and the $\mathrm{V}_{\text {ambient }}(\mathrm{t})$ was sampled. This results in Equation 7 being modified further to: 


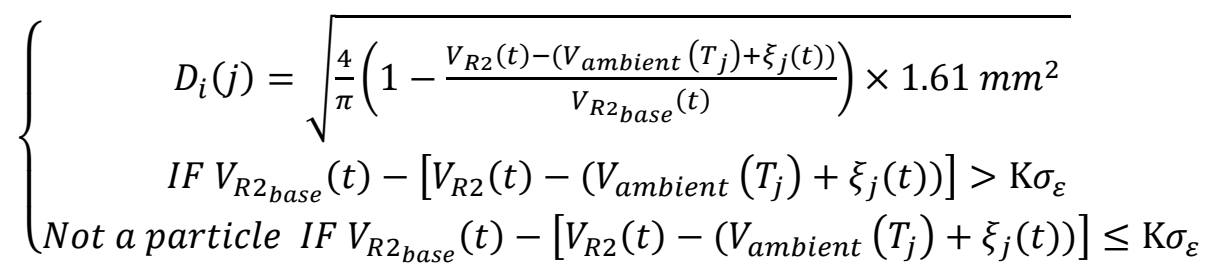

where $\xi_{j}(t)$ is intended to represent the error associated with using $V_{\text {ambient }}\left(T_{j}\right)$, which is estimated from sampling the $V_{R 2}$ signal at a distinctly different time than $t$. The magnitude of $\xi_{j}(t)$ is unknown at this time, but will become better quantified after field trials are completed with OGDs under ambient lighting conditions. As a rule, the more frequently the "dark signal" is collected, the smaller the value of $\xi_{\mathrm{j}}(\mathrm{t})$ is expected to be. These concepts are illustrated in Figure 9, which shows a sample time series of data collected with an OGD that was operated outdoors with a data collection rate of $10 \mathrm{kHz}$. The device was intentionally moved around in orientation to simulate varying contributions of ambient light to $V_{R 2}(t)$. To illustrate the concept of "dark signal" the OGD diode was switched off for $5 \mathrm{~ms}$ every $100 \mathrm{~ms}$ and turned back on for the remaining $95 \mathrm{~ms}$. If the overall light input into the phototransistor is within the range of linear behavior, then the measurement of $\mathrm{V}_{\mathrm{R} 2}$ during the time that the photodiode is off can be used to correct the value of $\mathrm{V}_{\mathrm{R} 2}$ when the photodiode is on and actively sensing sand grain movement (per Equation 9 if $\xi_{\mathrm{j}}(\mathrm{t})$ can be assumed to be nearly zero). It is notable that $\mathrm{V}_{\mathrm{R} 2 \mathrm{base}}$ is expected to change over time, but that such changes are likely to occur over the timescale of minutes or longer since they relate to temperature fluctuations, degradation of the lenses that cover the emitter and sensor, and other relatively slow processes. Therefore, fast (sub-second) temporal changes in $\mathrm{V}_{\mathrm{R} 2}$ when it is known that there are no particles blocking the light beam can be attributed entirely to changes in $\mathrm{V}_{\text {ambient }}(\mathrm{t})$. This observation has the potential to be useful in further reducing $\xi_{\mathrm{j}}(\mathrm{t})$ to a workable value in future development efforts. 


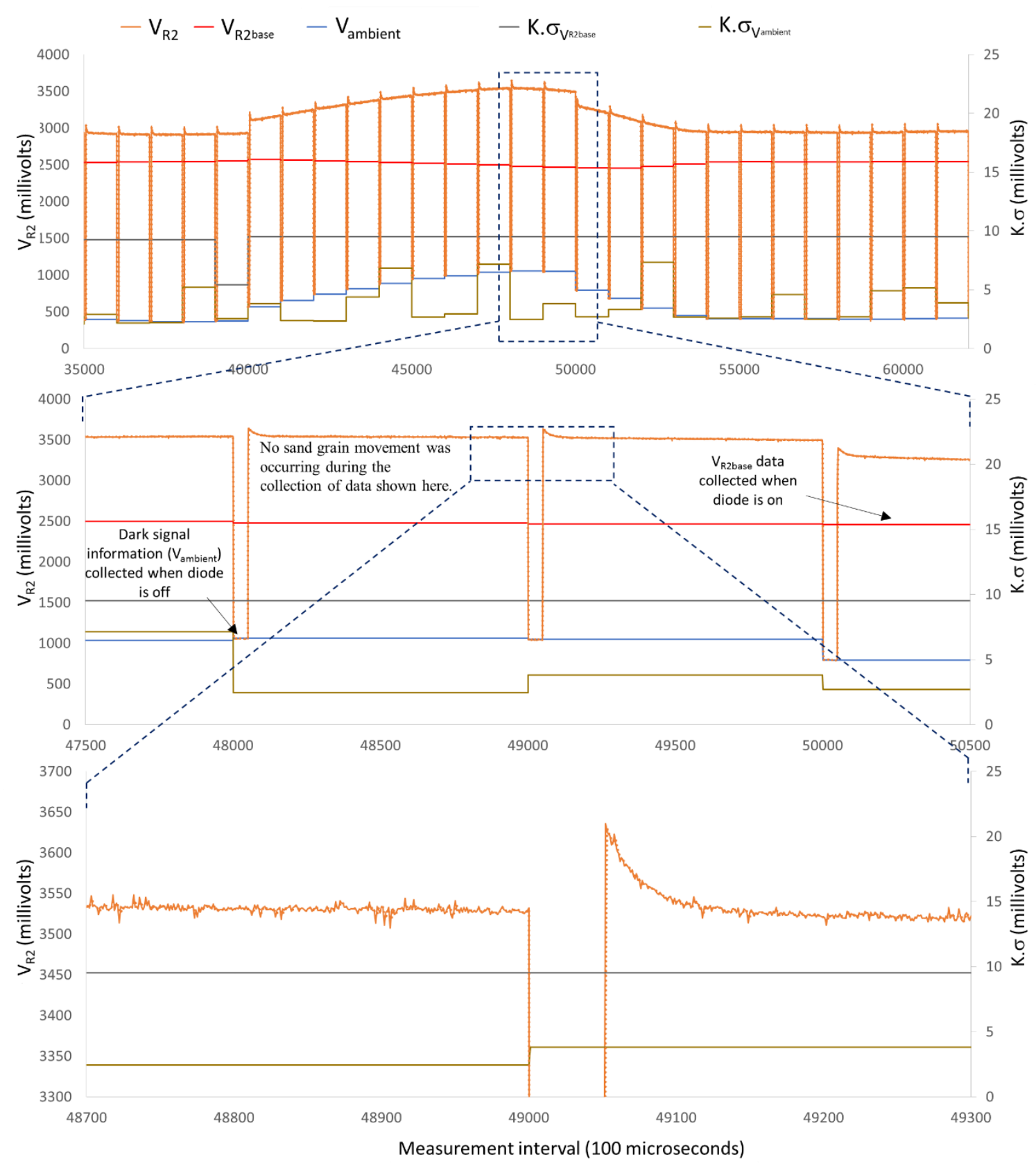

Figure 9. Time series of $V_{R 2}$ collected with OGD in an outdoor environment. The amount of incident ambient light was intentionally varied to demonstrate how $V_{R 2 b a s e}$ and related properties can be estimated from the dark signal and the combined dark and $V_{R 2 b a s e}$ signals $\left(V_{R_{2}}\right)$. The estimate of the dark signal is obtained during a time period when actual measurement of sand movement is not occurring and applied at a later time resulting in possible errors. Data were collected at $10 \mathrm{kHz}$. The infrared diode was turned off for 5 milliseconds and then turned on for $\mathbf{9 5}$ milliseconds, so that 10 measurements of the dark signal of 5 millisecond duration each were collected each second. Note overshoot of sensor shown in bottom panel for approximately 5 milliseconds following turning of photodiode on. No sand grain movement was occurring during the collection of data shown here. 
There are several additional points that can be gleaned from Figure 9. Related to the discussion above, if counting the number of detectable particles that cross the light beam in the optical gate is the main objective, then a simple median filter can be used for peak detection, provided that the occurrence of beam blockage was relatively rare and that most of the time that $V_{R 2}$ is being sampled corresponds to the sum of $V_{R 2 b a s e}$ and $V_{\text {ambient }}$. In this case abrupt changes such as the one highlighted over the 0.3 seconds in the top panel would only result in a small error in the number of particles identified. However, if interpreting the magnitude of the signal with the aim of inferring size distributions and other properties of the particles (related to symmetry and shape, perhaps) was the main objective, then knowing the relative magnitude of $\mathrm{V}_{\mathrm{R} 2 \mathrm{base}}$ and $\mathrm{V}_{\text {ambient }}$ becomes important. The second point is that if $\mathrm{V}_{\text {ambient }}$ is direct light from a single source (i.e., not diffuse), then the blockage of that light caused by a particle will register as a dip in the $\mathrm{V}_{\mathrm{R} 2}$ signal and it will not be possible to differentiate between a particle that blocks light from the IR diode and one that blocks light from an ambient source (likely the sun). This further underscores the importance of minimizing the chances of direct sunlight impinging on the sensor.

A final point about Figure 9 is that the signal from the phototransistor appears to respond very quickly to the turning off of the diode (essentially instantaneous). However, when the diode is turned on there appears to be an initial spike in the phototransistor signal that decays over about $5 \mathrm{~ms}$ before a steady baseline signal is achieved (see Figure 9 bottom panel for close-up). It is likely that this spike is caused by the IR diode initially providing a spike in light before settling to a longer term steady state value. Figure 10 demonstrates that the response time for the phototransistor is quite fast, with the signal going from zero to $\mathrm{V}_{\mathrm{R} 2 \mathrm{base}}$ in about $50 \mu$ s with a comparable time for returning to zero once the current to the photodiode goes to zero. Given that the aperture of the light beam across the optical gate is $1.27 \mathrm{~mm}$ $(0.00127 \mathrm{~m})$, then any particle traveling through the largest span of the aperture at speeds $<25 \mathrm{~m} \mathrm{~s}^{-1}$ will not escape detection $\left(0.00127 \mathrm{~m}\right.$ divided by $\left.25 \mathrm{~m} \mathrm{~s}^{-1} \approx 50 \mu \mathrm{s}\right)$ if it is large enough to exceed the threshold criteria (i.e., the signal change is more than $K \times \sigma_{\varepsilon}$ ). Particles traveling faster than $>25 \mathrm{~m} \mathrm{~s}^{-1}$ are more likely 
to elude detection. Note that this assumes that signal acquisition rate is also high enough (i.e., at least 20 $\mathrm{kHz}$ ) not to miss any particles. It remains to be seen if there is the prospect of estimating the travel speed of particles moving at slower speeds (i.e., $<25 \mathrm{~m} \mathrm{~s}^{-1}$ ) through the optical gate with some accuracy.

\subsection{Further considerations for the success of OGD deployment}

Two questions remain somewhat unaddressed at this time. What is the practical upper limit of sand flux that can be measured with the OGD device that was tested here before the sensor becomes saturated with particles? That is, when is it no longer possible to differentiate individual particles going through the sensing volume because it is frequently more than a single particle that is in the path of the light beam at any given time? It is known from the use of these devices inside of the PI-SWERL ${ }^{\circledR}$ instrument that such saturation does occur. However, due to the location of the OGD inside the PI$\mathrm{SWERL}^{\circledR}$ it is likely that they experience substantially enhanced interaction with sand grains compared to sand transport under typical aeolian conditions driven by atmospheric processes. It is also known that the Wenglor $^{\circledR}$ device is also susceptible to saturation (e.g., Hugenholtz and Barchyn, 2011; Sherman et al., 2011), but the width of the gate in those devices is several-fold larger than the OGD tested here so that the incidence of multiple grains within the sensing volume is proportionately greater. Therefore, it is unknown if saturation of the OPB800W55Z OGD could occur under normal aeolian transport conditions. In any case, at low levels, such saturation (roughly corresponding to a third of the signal being associated with the presence of particles) would initially only impact the ability to count individual particles. The magnitude of $V_{R 2}(t)$ could still be related to a useful measure of sand transport provided that $V_{R 2 b a s e}$ remains known- that is, the signal integral can be used as a measure of sand movement in place of counts of individual sand particles (See Figure 6b).

The second outstanding question is how does the behavior of the OGD sensors change over time as the optical lenses that protect the emitter and sensor are degraded by abrasion, the presence of UV light, or blockage by accumulation of dust particles or other types of debris on the lenses? All of the 
information that has been presented here has been derived from testing OGD that are new and have experienced minimal amounts of the types of duress that can arise under field conditions. The ways in which the sensor properties change over time should be better characterized in future work.

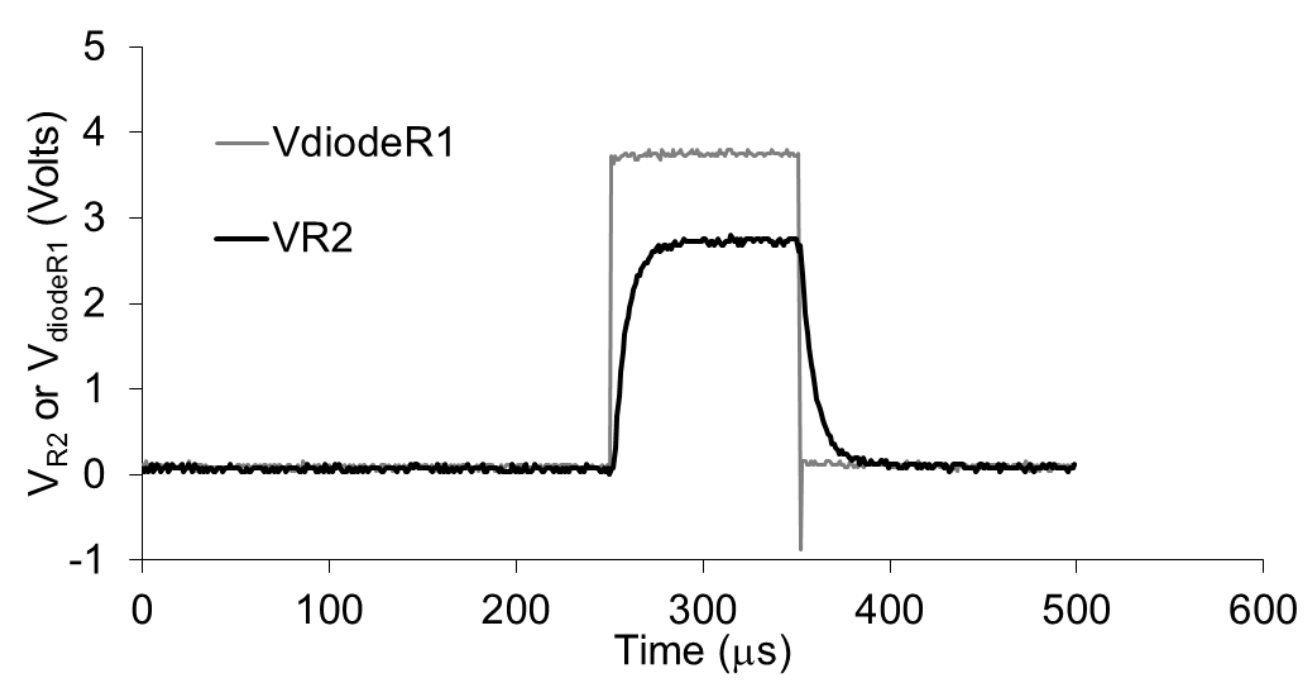

Figure 10. Response of phototransistor $\left(V_{R 2}\right)$ to sudden change in current $\left(V_{\text {diode_in }}\right)$ through the infrared diode. Change in diode was effected with a square pulse while $V_{\text {in }}$ was maintained constant for the phototransistor.

\subsection{Comparison with Wenglor ${ }^{\circledR}$ sensor}

Although this work has been focused on the characteristics of the OPB800W55Z, the more widespread use of the Wenglor ${ }^{\circledR}$ OGD does warrant some discussion of that sensor as well. The Wenglor ${ }^{\circledR}$ has been shown to provide particle counts that for a given height and sediment composition are proportional to the mass flux as measured in wind tunnel tests (Barchyn et al., 2014) and field tests (Martin et al., 2016). With some consideration of the size distribution of the sediment, these particle counts can be transformed into an estimate of mass flux using physical principles and not just through empirical relationships (Barchyn et al., 2014). Simply, this suggests that under favorable conditions, the Wenglor $^{\circledR}$ sensor is well capable of counting the particles in the sizes that contribute to the mass flux.

Drawbacks of the Wenglor ${ }^{\circledR}$ that have been reported include that the sensor requires relatively frequent cleaning, does not work well in dusty conditions, and that it gives spurious count data frequently 
enough that sensors ought to always be used in pairs so that the information from one can be checked against the other (Barchyn et al., 2014; Hugenholtz and Barchyn, 2011; Martin et al., 2016). However, in light of our discussion in earlier sections, it may be that all of these stem from what is perhaps the overarching disadvantage of the Wenglor ${ }^{\circledR}$ sensors, at least as they have been reportedly used to date, which is that the signal processing occurs entirely within the sensor housing, with some limited input from the User (such as the "Teach-in" feature, wherein the threshold for counting can be adjusted).

Noting that the Wenglor ${ }^{\circledR}$ has a fast response (inferred from the high sampling rate of the sensor per manufacturer's information) the same criteria outlined in Table 1 and applied to the Optek OGD would have to be shown to apply to the Wenglor "raw" signal. Importantly, the signal response would have to be demonstrated to be proportional to the fraction of the beam that is blocked (in any region) as well as the intensity of light that the source is producing (this is the basic linearity criterion). If this significant criterion can be shown to be met by the Wenglor ${ }^{\circledR}$ device, then effect of the soiling of the lenses, the diminishment of the light beam over time, the influence of incident sunlight and other shortterm interferences, can all be corrected for to a certain degree and the count data from the sensor can become more reliable. Moreover, information about particle speed and size can also become a possibility, perhaps eventually obviating the need to simultaneously measure sediment flux with a mass-based device.

Of course, it is the simplicity of its use that has been one of the most attractive features of the Wenglor $^{\circledR}$ to the aeolian transport community. Nevertheless, while individual scientists will not all have the resources to conduct signal processing similar to what is described here, once there is some consensus on how it should be accomplished, it may be possible to simply procure supplemental electronics that will perform the task.

There are at least two, physically plausible conditions that cannot be improved upon by having access to the raw signal of any OGD device. If the photosensor is completely saturated by incoming light (e.g., direct sunlight incidence) so that the signal is forced to its limit value", we are unware of any way to 
extract useful information from the OGD. At the other extreme, if the light beam is essentially completely blocked by particles moving through the air under conditions of high transport, then there is no way of estimating the magnitude of that transport other than to note that it is greater than what is required to overwhelm that specific OGD. These two conditions can be addressed only through engineering controls and not through signal processing techniques.

\section{CONCLUSIONS AND FUTURE WORK}

The OGD described here appears to be well suited for future development of a sand transport measuring device. Empirical measurements in the wind tunnel of sand flux by NSTs simultaneous with counts of pulses in the signal of the OGD yielded well-correlated results. Similarly correlated results were found when comparing the integral of the signal over time to the sand flux. Additional empirical tests of multiple OGDs (8) showed that the measurements among the different units were highly correlated. Combined, these two pieces of information answered the high level questions: "Is the measurement repeatable among different units? And can the measurement be correlated to an established standard for sand flux measurement?" Positive indicators for both these questions motivated additional, more directed characterization of the Optek OPB800W55Z, one of many optical gate sensors available on the market, but one that has already undergone substantial testing.

Specific tests and analyses were completed to ascertain sensor linearity in the normal zone of operation, noise levels, interferences from ambient light, and response time. Critically, there is a zone of operation for the sensor where the response to light incident on the sensor is linear. This allows for background-correcting the signal for stray ambient light. It also allows for interpretation of the signal magnitude in the context of specific particle sizes. It is possible for ambient stray light to reach high enough levels to render the signal response non-linear and even to completely saturate the sensors (i.e., no change with additional light input). Accordingly, when configuring OGDs for field use, the potential for ambient light to be incident on the sensor should be minimized. If operating in the linear zone, corrections 
for ambient light artifacts can be made by measuring the signal when the diode emitter is off ("dark signal") so that the signal detected is entirely a result of the ambient light.

Equally as important as electronic linearity, data provided by the manufacturer's data sheets indicate that the sensor response is relatively spatially homogeneous. That is, blocking a specific area of the sensor's aperture at any location within the aperture gives the same response in sensor signal. There are some subtle deviations from this ideal that are evident from the data given by the manufacturer, but it is not clear if these vary from unit to unit.

Electronic noise levels associated with signal from the sensor being inside the laboratory were about a third of what they were when measurements were collected outside. The minimum size of sand grain that is detectable depends on the level of false positives that is acceptable, but without any further improvements in signal quality, setting the detection limit to three standard deviations of the noise signal translates roughly to a lower particle size of $90 \mu \mathrm{m}$. It is estimated that the lower limit for detecting individual particles may be closer to about $65 \mu \mathrm{m}$ once improvements in signal conditioning have been implemented. However, this is only a guess at this juncture.

Very small particles, such as in the dust and small silt range, are likely to minimally impact the sensor's ability to recognize larger, sand-sized particles. Fairly high concentrations of dust would have the overall effect of lowering the baseline signal $\left(\mathrm{V}_{\mathrm{R} 2 \_ \text {base }}\right)$ and perhaps reducing sensitivity by a proportional amount. However, presumably such high dust conditions would be accompanied in most cases by very high sand fluxes when it is less likely that the measurement of sand flux would be hampered by slightly reduced sensitivity. Related to this point, at very high sand fluxes, there is the possibility that the OGD could be subject to particle saturation. In this case particles travelling through the sensing volume in large numbers would make it impossible to differentiate the effect of individual particles on the signal at any given time. It is unknown whether this particle saturation effect is likely to happen under real-world 
aeolian transport conditions.

Examination of the response time of the Optek OPB800W55Z indicated that the phototransistor response time to changes in incident light is on the order of $50 \mu \mathrm{s}$, both for increases and decreases in light intensity. In practice this means that the probability of detecting particles traveling through the sensing volume is more impacted by the data sampling rate, $10 \mathrm{kHz}$ in the most recent testing conditions, than by the sensor response time, which we estimate can accommodate particles that are traveling as fast as $25 \mathrm{~m} \mathrm{~s}^{-1}$ through the sensing volume, which is an unlikely high speed for particles during wind driven saltation.

This study has focused on determining the suitability of an OGD for conducting measurements of sand movement in aeolian sediment transport conditions. Alongside positive attributes and outcomes of this work, some potential weaknesses have been identified for further evaluation. They relate to the durability and related measurement reliability of these plastic devices as well as variability in signal linearity and signal response among different units of the same model. Another point is that the specific OGD model reported here was chosen early on for its desirable attributes. A systematic evaluation of all similar devices has not been undertaken to ensure that the Optek OPB800W55Z is among the most desirable. Related to this, it would useful too for a comparably systematic assessment of the Wenglor ${ }^{\circledR}$ signal characteristics to be undertaken as that sensor has already been used in numerous field and laboratory studies.

The ultimate question that has to be answered is whether these (and other) OGD-type devices, once configured optimally, are in fact superior to those that are already available for measurement of sediment transport, in cost, performance, ease-of-use, or a combination of these factors. A clear conclusion is that this example of an OGD sensor warrants further development at this time to include additional characterization. Several field deployable prototype instruments (SANTRITM) that use these OGDs have been assembled and are in the process of field testing. Results will provide important 35 
aggregate level comparisons among instruments and will undoubtedly unveil some shortcomings of the

OGD, or at least provide further guidance for future implementation.

\section{ACKNOWLEDGEMENTS}

This material is based upon work supported by the National Science Foundation under Grants No.

EAR-0840171 and EAR-1124609. Additional funding provided by the Department of Transportation through the SOLARIS University Transportation center through Grant number DTRT13-G-UTC55.

\section{REFERENCES}

Anderson, R.S., Hallet, B., 1986. Sediment transport by wind: Toward a general model. Geol. Soc. Am. Bull. 97, 523-535. doi:10.1130/0016-7606.

Andreotti, B., 2004. A two-species model of aeolian sand transport. J. Fluid Mech. 510, 47-70. doi:10.1017/S0022112004009073.

Baas, A.C.W., 2006. Wavelet power spectra of aeolian sand transport by boundary layer turbulence. Geophys. Res. Lett. 33, L05403. doi:10.1029/2005GL025547.

Baas, A.C.W., 2004. Evaluation of saltation flux impact responders (Safires) for measuring instantaneous aeolian sand transport intensity. Geomorphology, Aeolian Research: processes, instrumentation, landforms and palaeoenvironments 59, 99-118. doi:10.1016/j.geomorph.2003.09.009.

Baas, A.C.W., Sherman, D.J., 2005. Formation and behavior of aeolian streamers. J. Geophys. Res. Earth Surf. 110, F03011. doi:10.1029/2004JF000270.

Bagnold, R.A., 1941. The physics of blown sand and desert dunes,. Methuen \& Co., London.

Bagnold, R.A., 1936. The movement of desert sand, in: Proceedings of the Royal Society of London. pp. 594-620.

Barchyn, T.E., Hugenholtz, C.H., Li, B., Neuman, C.M., Sanderson, S., 2014. From particle counts to flux: Wind tunnel testing and calibration of the "Wenglor" aeolian sediment transport sensor. Aeolian Res. 15, 311-318. doi:10.1016/j.aeolia.2014.06.009.

Butterfield, G.R., 1999. Near-bed mass flux profiles in aeolian sand transport: high-resolution measurements in a wind tunnel. Earth Surf. Process. Landf. 24, 393-412. doi:10.1002/(SICI)1096-9837(199905)24:53.0.CO;2-G.

Crawley, D.M., Nickling, W.G., 2003. Drag partition for regularly-arrayed rough surfaces. Bound.-Layer Meteorol. 107, 445-468.

Davidson-Arnott, R., Bauer, B.O., Walker, I.J., Hesp, P.A., Ollerhead, J., Delgado-Fernandez, I., 2009. Instantaneous and mean aeolian sediment transport rate on beaches: An intercomparison of measurements from two sensor types. J. Coast. Res. 297-301.

Davidson-Arnott, R.G.D., Bauer, B.O., 2009. Aeolian sediment transport on a beach: Thresholds, intermittency, and high frequency variability. Geomorphology, Contemporary research in aeolian geomorphology6th International Conference on Aeolian Research (ICAR VI) 105, 117-126. doi:10.1016/j.geomorph.2008.02.018.

Dong, Z., Qian, G., 2006. Characterizing the height profile of the flux of wind-eroded sediment. Environ. Geol. 51, 835-845. doi:10.1007/s00254-006-0363-5.

Dong, Z., Qian, G., Luo, W., Wang, H., 2006. Analysis of the mass flux profiles of an aeolian saltating cloud. J. Geophys. Res. Atmospheres 111, D16111. doi:10.1029/2005JD006630.

Ellis, J.T., Morrison, R.F., Priest, B.H., 2009. Detecting impacts of sand grains with a microphone system 
in field conditions. Geomorphology, Contemporary research in aeolian geomorphology6th International Conference on Aeolian Research (ICAR VI) 105, 87-94.

doi:10.1016/j.geomorph.2008.02.017.

Etyemezian, V., Nikolich, G., Ahonen, S., Pitchford, M., Sweeney, M., Purcell, R., Gillies, J., Kuhns, H., 2007. The Portable In Situ Wind Erosion Laboratory (PI-SWERL): A new method to measure PM10 potential for windblown dust properties and emissions. Atmos. Environ. 41, 3789-3796. doi:10.1016/j.atmosenv.2007.01.018.

Gillette, D., 1977. Fine particulate-emissions due to wind erosion. Trans. Asae 20, 890-897.

Gillette, D.A., Herbert, G., Stockton, P.H., Owen, P.R., 1996. Causes of the fetch effect in wind erosion. Earth Surf. Process. Landf. 21, 641-659. doi:10.1002/(SICI)1096-9837(199607)21:73.0.CO;2-9.

Gillette, D., Stockton, P., 1989. The effect of nonerodible particles on wind erosion of erodible surfaces. J. Geophys. Res.-Atmospheres 94, 12885-12893. doi:10.1029/JD094iD10p12885.

Gillies, J.A., Nickling, W.G., King, J., 2006. Aeolian sediment transport through large patches of roughness in the atmospheric inertial sublayer. J. Geophys. Res.-Earth Surf. 111, F02006. doi:10.1029/2005JF000434.

Gillies, J.A., Nickling, W.G., Tilson, M., 2013. Frequency, magnitude, and characteristics of aeolian sediment transport: McMurdo Dry Valleys, Antarctica. J. Geophys. Res.-Earth Surf. 118, 461479. doi:10.1002/jgrf.20007.

Goossens, D., Offer, Z., London, G., 2000. Wind tunnel and field calibration of five aeolian sand traps. Geomorphology 35, 233-252. doi:10.1016/S0169-555X(00)00041-6.

Greeley, R., Blumberg, D.G., Williams, S.H., 1996. Field measurements of the flux and speed of windblown sand. Sedimentology 43, 41-52. doi:10.1111/j.1365-3091.1996.tb01458.x.

Haustein, K., Washington, R., King, J., Wiggs, G., Thomas, D.S.G., Eckardt, F.D., Bryant, R.G., Menut, L., 2015. Testing the performance of state-of-the-art dust emission schemes using DO4Models field data. Geosci. Model Dev. 8, 341-362. doi:10.5194/gmd-8-341-2015.

Hugenholtz, C.H., Barchyn, T.E., 2011. Laboratory and field performance of a laser particle counter for measuring aeolian sand transport. J. Geophys. Res. Earth Surf. 116, F01010. doi:10.1029/2010JF001822.

Ishizuka, Mikami, M., Leys, J., Yamada, Y., Heidenreich, S., Shao, Y., McTainsh, G.H., 2008. Effects of soil moisture and dried raindroplet crust on saltation and dust emission. J. Geophys. Res. Atmospheres 113, D24212. doi:10.1029/2008JD009955.

Jackson, D.W.T., 1996. A new, instantaneous aeolian sand trap design for field use. Sedimentology 43, 791-796. doi:10.1111/j.1365-3091.1996.tb01502.x.

Kandler, K., Schütz, L., Deutscher, C., Ebert, M., Hofmann, H., Jäckel, S., Jaenicke, R., Knippertz, P., Lieke, K., Massling, A., Petzold, A., Schladitz, A., Weinzierl, B., Wiedensohler, A., Zorn, S., Weinbruch, S., 2009. Size distribution, mass concentration, chemical and mineralogical composition and derived optical parameters of the boundary layer aerosol at Tinfou, Morocco, during SAMUM 2006. Tellus B 61, 32-50. doi:10.1111/j.1600-0889.2008.00385.x.

Kurosaki, Y., Mikami, M., 2007. Threshold wind speed for dust emission in east Asia and its seasonal variations. J. Geophys. Res. Atmospheres 112, D17202. doi:10.1029/2006JD007988.

Lancaster, N., Nickling, W.G., Gillies, J.A., 2010. Sand transport by wind on complex surfaces: Field studies in the McMurdo Dry Valleys, Antarctica. J. Geophys. Res.-Earth Surf. 115, F03027. doi:10.1029/2009JF001408.

Leonard, K.C., Cullather, R.I., 2008. Snowfall measurements in the Amundsen and Bellingshausen Seas, Antarctica, in: Proceedings of the Eastern Snow Conference. pp. 87-98.

Li, Z.S., Ni, J.R., 2003. Sampling efficiency of vertical array aeolian sand traps. Geomorphology 52, 243-252. doi:10.1016/S0169-555X(02)00259-3.

Martin, R.L., Kok, J.F., Chamecki, M., 2016. High-frequency field observations of aeolian saltation interactions with turbulent boundary layer winds. ArXiv160908707 Phys. 
Mikami, M., 2005. Measurement of soil water content in a hyper-arid environment using time-domain reflectometry sensors. Hydrol. Process. 19, 3911-3920. doi:10.1002/hyp.5989.

Mikami, M., Yamada, Y., Ishizuka, M., Ishimaru, T., Gao, W., Zeng, F., 2005. Measurement of saltation process over gobi and sand dunes in the Taklimakan desert, China, with newly developed sand particle counter. J. Geophys. Res. Atmospheres 110, D18S02. doi:10.1029/2004JD004688.

Mitha, S., Tran, M.Q., Werner, B.T., Haff, P.K., 1986. The grain-bed impact process in aeolian saltation. Acta Mech. 63, 267-278. doi:10.1007/BF01182553.

Namikas, S.L., 2003. Field measurement and numerical modelling of aeolian mass flux distributions on a sandy beach. Sedimentology 50, 303-326. doi:10.1046/j.1365-3091.2003.00556.x.

Namikas, S.L., 2002. Field Evaluation of Two Traps for High-Resolution Aeolian Transport Measurements. J. Coast. Res. 18, 136-148.

Nickling, W.G., McKenna Neuman, C., 1997. Wind tunnel evaluation of a wedge-shaped aeolian sediment trap. Geomorphology 18, 333-345. doi:10.1016/S0169-555X(96)00040-2.

O’Brien, P., McKenna Neuman, C., 2012. A wind tunnel study of particle kinematics during crust rupture and erosion. Geomorphology 173-174, 149-160. doi:10.1016/j.geomorph.2012.06.005.

Ono, D., Weaver, S., Richmond, K., 2003. Quantifying particulate matter emissions from wind blown dust using real-time sand flux measurements. Owens Emiss. Pap. Pap.-C EPA.

Poortinga, A., van Rheenen, H., Ellis, J.T., Sherman, D.J., 2015. Measuring aeolian sand transport using acoustic sensors. Aeolian Res. 16, 143-151. doi:10.1016/j.aeolia.2014.12.003.

Rajot, J.L., Alfaro, S.C., Gomes, L., Gaudichet, A., 2003. Soil crusting on sandy soils and its influence on wind erosion. CATENA 53, 1-16. doi:10.1016/S0341-8162(02)00201-1.

Shao, Y., 2005. A Similarity Theory for Saltation and Application to Aeolian Mass Flux. Bound.-Layer Meteorol. 115, 319-338. doi:10.1007/s10546-004-4632-0.

Sherman, D.J., Li, B., Farrell, E.J., Ellis, J.T., Cox, W.D., Maia, L.P., Sousa, P.H.G.O., 2011. Measuring Aeolian saltation: A comparison of sensors. J. Coast. Res. 59, 280-290. doi:10.2112/SI59-030.1.

Shinoda, M., Gillies, J.A., Mikami, M., Shao, Y., 2011. Temperate grasslands as a dust source: Knowledge, uncertainties, and challenges. Aeolian Res. 3, 271-293. doi:10.1016/j.aeolia.2011.07.001.

Sørensen, M., 2004. On the rate of aeolian sand transport. Geomorphology, Aeolian Research: processes, instrumentation, landforms and palaeoenvironments 59, 53-62. doi:10.1016/j.geomorph.2003.09.005.

Spaan, W.P., van den Abeele, G.D., 1991. Wind borne particle measurements with acoustic sensors. Soil Technol. 4, 51-63. doi:10.1016/0933-3630(91)90039-P.

Sterk, G., Jacobs, A.F.G., Van Boxel, J.H., 1998. The effect of turbulent flow structures on saltation sand transport in the atmospheric boundary layer. Wind Eros. Sahelian Zone Niger Process. Models Control Tech. 11.

Stout, J.E., Zobeck, T.M., 1996. The Wolfforth field experiment: a wind erosion study. Soil Sci. 161, 616-632.

Sweeney, M., Etyemezian, V., Macpherson, T., Nickling, W., Gillies, J., Nikolich, G., McDonald, E., 2008. Comparison of PI-SWERL with dust emission measurements from a straight-line field wind tunnel. J. Geophys. Res.-Earth Surf. 113, F01012. doi:10.1029/2007JF000830.

Sweeney, M.R., Mason, J.A., 2013. Mechanisms of dust emission from Pleistocene loess deposits, Nebraska, USA: Dust emission from loess. J. Geophys. Res. Earth Surf. 118, 1460-1471. doi:10.1002/jgrf.20101.

Ungar, J.E., Haff, P.K., 1987. Steady state saltation in air. Sedimentology 34, 289-299. doi:10.1111/j.1365-3091.1987.tb00778.x.

Van Pelt, R.S., Peters, P., Visser, S., 2009. Laboratory wind tunnel testing of three commonly used saltation impact sensors. Aeolian Res. 1, 55-62. doi:10.1016/j.aeolia.2009.05.001.

Visser, S.M., Sterk, G., Snepvangers, J.J.J.C., 2004. Spatial variation in wind-blown sediment transport in 
geomorphic units in northern Burkina Faso using geostatistical mapping. Geoderma 120, 95-107. doi:10.1016/j.geoderma.2003.09.003.

Weaver, C.M., Wiggs, G.F.S., 2011. Field measurements of mean and turbulent airflow over a barchan sand dune. Geomorphology 128, 32-41. doi:10.1016/j.geomorph.2010.12.020.

Weinan, C., Zuotao, Y., Jiashen, Z., Zhiwen, H., 1996. Vertical Distribution of Wind-Blown Sand Flux in the Surface Layer, Taklamakan Desert, Central Asia. Phys. Geogr. 17, 193-218. doi:10.1080/02723646.1996.10642581.

Xing, M., 2007. The harmonious character in equilibrium aeolian transport on mixed sand bed. Geomorphology 86, 230-242. doi:10.1016/j.geomorph.2006.08.015.

Zhang, W., Wang, Y., Lee, S.-J., 2007. Two-phase measurements of wind and saltating sand in an atmospheric boundary layer. Geomorphology 88, 109-119. doi:10.1016/j.geomorph.2006.10.017.

Zou, X.-Y., Wang, Z.-L., Hao, Q.-Z., Zhang, C.-L., Liu, Y.-Z., Dong, G.-R., 2001. The distribution of velocity and energy of saltating sand grains in a wind tunnel. Geomorphology 36, 155-165. doi:10.1016/S0169-555X(00)00038-6. 